\title{
Predicting the Gas Recovery for Hydraulically Fractured Horizontal Wells in Shale Reservoirs
}

Aymen A.B Ali Alhemdi

Follow this and additional works at: https://researchrepository.wvu.edu/etd

\section{Recommended Citation}

Alhemdi, Aymen A.B Ali, "Predicting the Gas Recovery for Hydraulically Fractured Horizontal Wells in Shale Reservoirs" (2014). Graduate Theses, Dissertations, and Problem Reports. 5067.

https://researchrepository.wvu.edu/etd/5067

This Thesis is protected by copyright and/or related rights. It has been brought to you by the The Research Repository @ WVU with permission from the rights-holder(s). You are free to use this Thesis in any way that is permitted by the copyright and related rights legislation that applies to your use. For other uses you must obtain permission from the rights-holder(s) directly, unless additional rights are indicated by a Creative Commons license in the record and/ or on the work itself. This Thesis has been accepted for inclusion in WVU Graduate Theses, Dissertations, and Problem Reports collection by an authorized administrator of The Research Repository @ WVU. For more information, please contact researchrepository@mail.wvu.edu. 


\title{
Predicting the Gas Recovery for Hydraulically Fractured Horizontal Wells in Shale Reservoirs
}

\author{
Aymen A.B Ali Alhemdi
}

\author{
Thesis submitted to the \\ Benjamin M.Statler College of Engineering and Mineral Resources \\ At West Virginia University \\ In partial fulfillment of the requirements for the degree of \\ Master of Science \\ In \\ Petroleum and Natural Gas Engineering
}

Kashy Aminian, Ph.D. Committee Chair

Samuel Ameri, M.S.

Allan Wallace Brannon, Ph.D.

Department of Petroleum and Natural Gas Engineering

Morgantown, West Virginia

2014

Keywords: [Unconventional reservoirs, Marcellus shale, Horizontal Wells with multiple hydraulic fractures, Gas recovery ratio]

Copyright 2014 Aymen Alhemdi 


\section{ABSTRACT \\ Predicting the Gas Recovery for Hydraulically Fractured Horizontal Wells in Shale Reservoirs}

\section{Aymen A.B Ali Alhemdi}

The increasing demand of energy and the limited reserves of conventional reservoirs leads the industry to enhance and develop low permeability reservoirs in recent years which become increasingly important than ever before. Shale gas one of these reservoirs which has very low permeability and the production from this formation has been and continues to be challenging. Horizontal wells with multiple hydraulic fractures are the proven technology to produce economically from gas shale formations. One of the issues in shale gas reservoirs is to have an accurate and reliable estimation of ultimate recovery.

The purpose of this research was to use the initial production history of Marcellus shale in order to predict the ultimate gas recovery of multiple fractured horizontal wells. A commercial reservoir simulator was utilized to create reservoir model with horizontal well fractured in multi stages.

The impacts of a number of reservoir and fractures parameters were investigated. Matrix porosity, number of hydraulic fracture stages, and fracture half-length were found to impact on the gas recovery. 


\section{ACKNOWLEDGEMENTS}

I would like to express my grateful thanks to Dr. Kashy Aminian first for being my academic advisor. His experience in oil and gas industry, commitment, patience with me, encouragement throughout finishing this research, guidance and explanations has made this research come to existence.

In addition, I want to offer my appreciation to my committee members. First, Professor Sam Ameri, Chairman of the PNGE Department, for his guidance and advice during my study at West Virginia University, his support and continuous motivation was a wonderful asset. Thanks, also goes to Dr. Alan Wallace Brannon for taking the time to be involved in the examining committee. Their valued contribution to this review is highly appreciated

Also, my appreciation extends to the other professors of the petroleum and natural gas department who motivated me throughout my M.S. program and transferring technical knowledge. I really want to express special thanks to all my friends and colleagues at WVU for their support and help. 


\section{DEDICATION}

My deepest gratefulness goes to my parents Abdullah and Dehiba for their unflagging love and unconditional support throughout my life and my studies I cannot thank you enough, May Allah protect them. I can't go on any further without thanking the rest of my family, brothers and sisters for their encouragement. I would like to dedicate my master to my dear wife Asma who stopped her study for me and my sweet son Sohib. Thank you for your help, support and endless motivation through entire my study. 


\section{TABLE OF CONTENT}

ABSTRACT TENOWLEGEMENTS

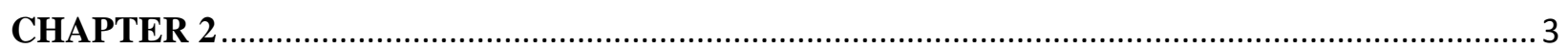

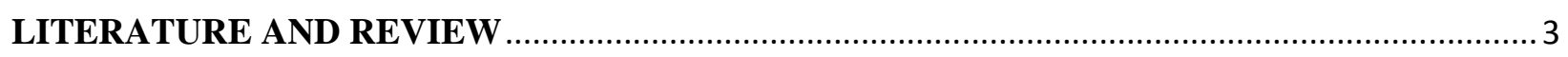

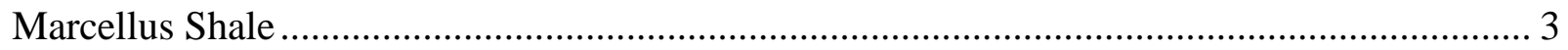

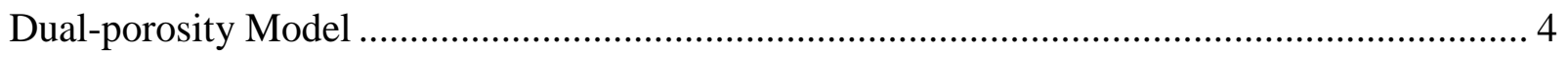

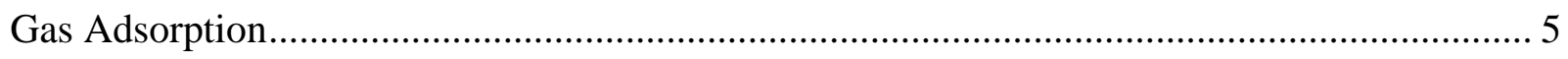

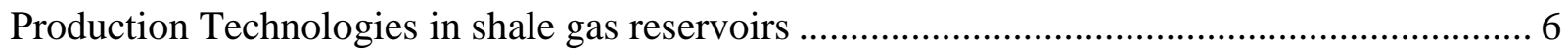

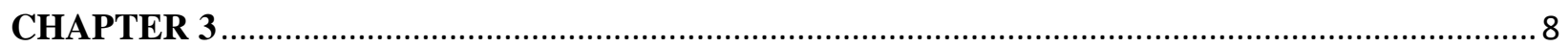

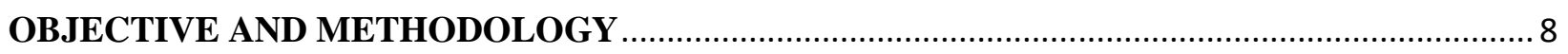

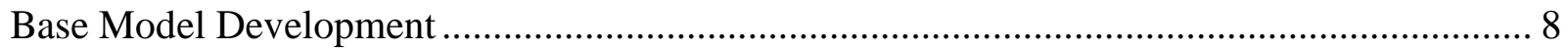

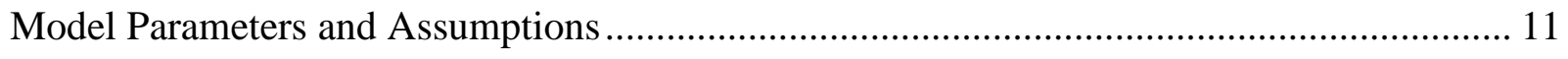

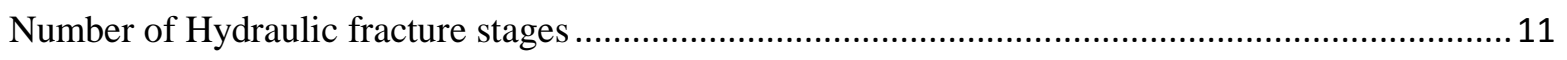

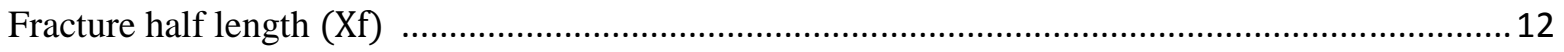

Matrix porosity $(\varnothing \mathrm{m})$

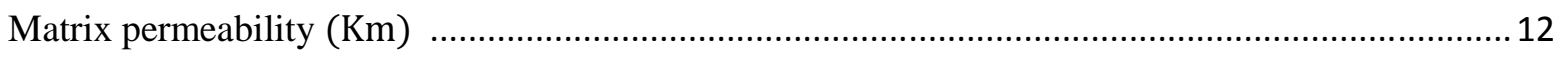

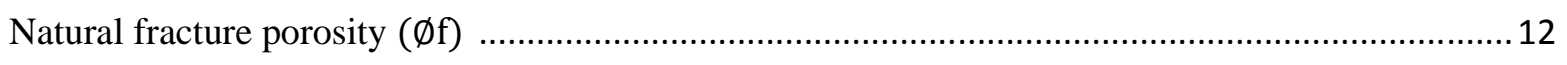

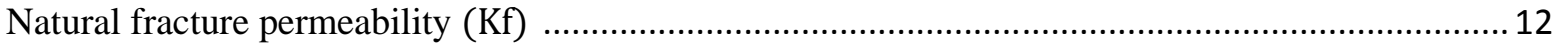

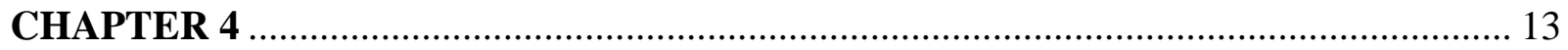

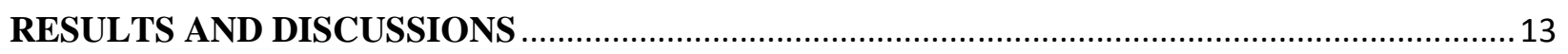

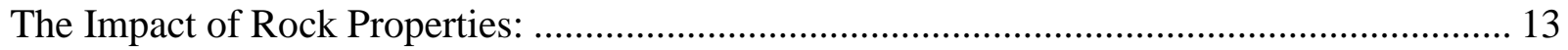

$>$ Matrix permeability $(\mathrm{Km})$ and Fracture porosity $(\varnothing \mathrm{f})$ Impact............................................... 13

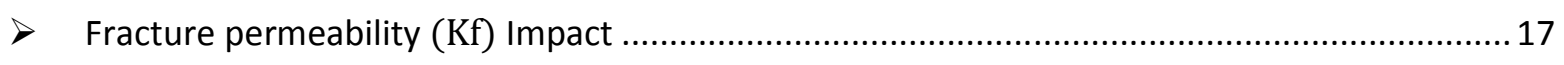

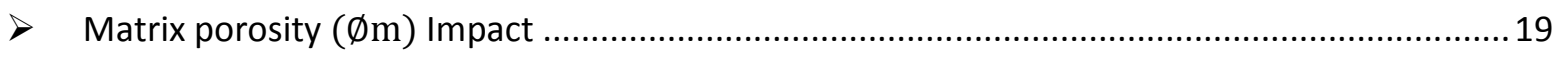

The Impact of Number of Hydraulic Fractures ............................................................. 21 


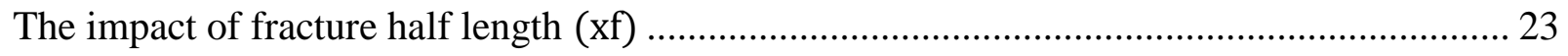

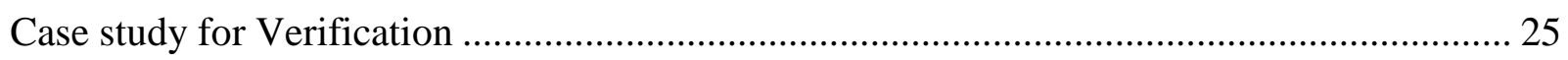

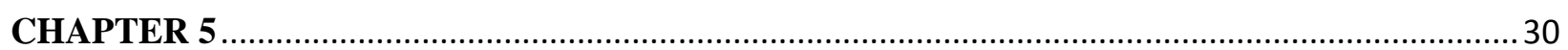

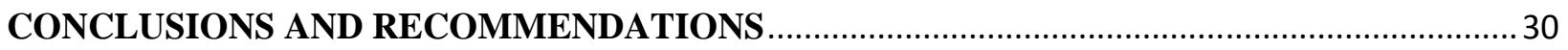

REFERENCES

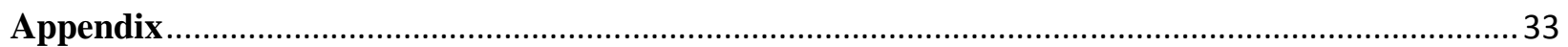




\section{LIST OF TABLES}

Table 1 Parameters and values used in the base model .................................................................... 10

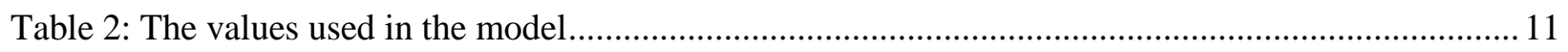

Table 3: Used values for fracture porosity and matrix permeability ................................................ 14

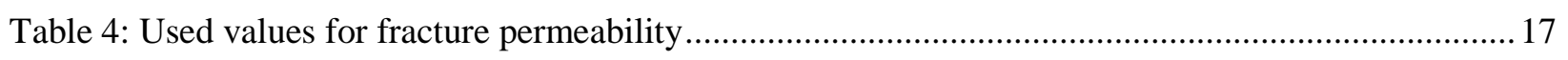

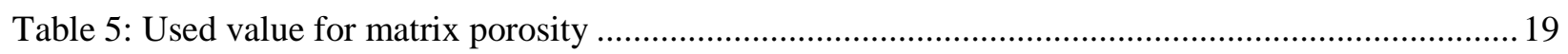

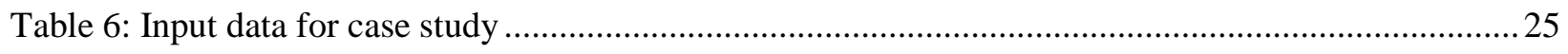

Table 7: Compare the result from the correlations and the simulator using first year recovery ratio.........26

Table 8: Compare the result from the correlations and the simulator using second year recovery ratio ....27

Table 9: Compare the result from the correlations and the simulator using Third year recovery ratio ......227 


\section{LIST OF FIGURES}

Figure 1: Unconventional gas reservoir locations (Total, 2012)...................................................... 1

Figure 2: Distribution of the Marcellus Shale Formation (The Wall Street Journal, 2011)....................... 3

Figure 3: Dual porosity as represented by the model (Grid block, www.dcs.gla.ac.uk, 2012).................. 4

Figure 4: Langmuir Isotherm (Reservoir, www.fekete.com) ........................................................ 6

Figure 5: Horizontal well with multiple hydraulic fractures (Shale gas diagram, www.ChartDiagram.com,

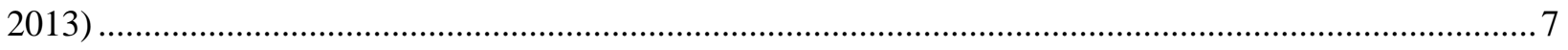

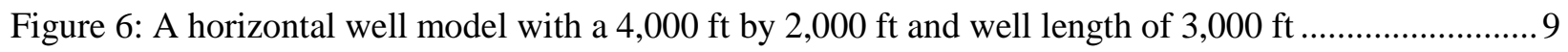

Figure 7: Impact matrix permeability on the recovery ratio for, 7-stage hydraulic fracture..................... 14

Figure 8: Impact matrix permeability on recovery ratio for 13 -stage hydraulic fracture.......................... 14

Figure 9: Impact matrix permeability on recovery ratio for 17 -stage hydraulic fracture.......................... 15

Figure 10: Impact natural fracture porosity on recovery ratio for 7 stage hydraulic fracture .................... 15

Figure 11: Impact natural fracture porosity on recovery ratio for 13-stage hydraulic fracture.................. 16

Figure 12: Impact natural fracture porosity on recovery ratio for 17 -stage hydraulic fracture................... 16

Figure 13: Impact natural fracture permeability on recovery ratio for 7-stage hydraulic fracture.............. 17

Figure 14: Impact natural fracture permeability on recovery ratio for 13-stage hydraulic fracture............ 18

Figure 15: Impact natural fracture permeability on recovery ratio for 17 -stage hydraulic fracture............ 18

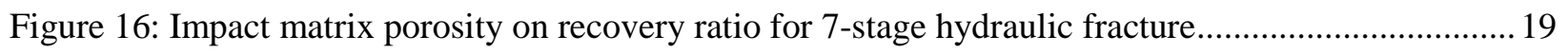

Figure 17: Impact matrix porosity on recovery ratio for 13 -stage hydraulic fracture ............................. 20

Figure 18: Impact matrix porosity on recovery ratio for 17 -stage hydraulic fracture.............................. 20

Figure 19: Impact the number of fractures on the recovery ratio based on $1^{\text {st }}$ year production................. 21

Figure 20: Impact the number of fractures on the recovery ratio based on $2^{\text {nd }}$ year production.................22

Figure 21: Impact the number of fractures on the recovery ratio based on $3^{\text {rd }}$ year production .................22

Figure 22: Impact Xf values on recovery ratio with different of $\emptyset m$ for 7-stage hydraulic fracture...........23

Figure 23: Impact Xf values on recovery ratio with different of $\emptyset \mathrm{m}$ for 13-stage hydraulic fracture ........ 24 
Figure 24: Impact Xf values on recovery ratio with different of $\emptyset \mathrm{m}$ for 17 -stage hydraulic fracture ........ 24

Figure 25: Correlation Q1/Q30 for 13-stage hydraulic fracture (case 1) ...............................................25

Figure 26: Correlation Q1/Q30 for fracture half length $500 \mathrm{ft}$. (case2) ...............................................26

Figure 27: Correlation Q2/Q30 for 13-stage hydraulic fracture (case1) .............................................2 27

Figure 28: Correlation Q2/Q30 for fracture half length $500 \mathrm{ft}$. (case2) ................................................28

Figure 29: Correlation Q3/Q30 for 13-stage hydraulic fracture (case1) ..............................................28

Figure 30: Correlation Q3/Q30 for fracture half length $500 \mathrm{ft}$. (case2) ................................................29

Figure 31: Impact Xf values on recovery ratio with different of $\emptyset \mathrm{m}$ for 7 -stage hydraulic fracture .......... 33

Figure 32: Impact Xf values on recovery ratio with different of $\emptyset \mathrm{m}$ for 13 -stage hydraulic fracture ......... 33

Figure 33: Impact Xf values on recovery ratio with different of $\emptyset \mathrm{m}$ for 17 -stage hydraulic fracture ........ 34

Figure 34: Impact Xf values on recovery ratio with different of $\emptyset \mathrm{m}$ for 7 -stage hydraulic fracture .......... 34

Figure 35: Impact Xf values on recovery ratio with different of $\emptyset \mathrm{m}$ for 13 -stage hydraulic fracture ........ 35

Figure 36: Impact Xf values on recovery ratio with different of $\emptyset \mathrm{m}$ for 17 -stage hydraulic fracture ......... 35

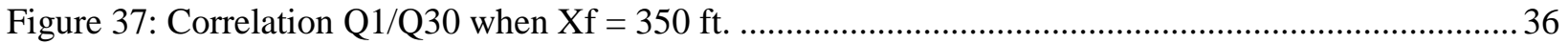

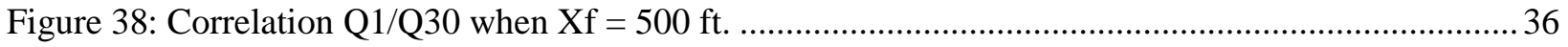

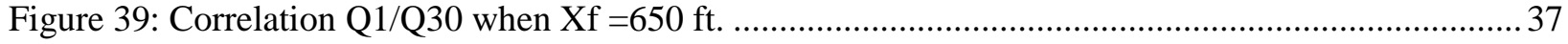




\section{LIST OF SYMBOLS/NOMENCLATURES}

$\operatorname{Pr}=$ Reservoir pressure, $\mathrm{psi}$

Pwf $=$ Bottom-hole flowing pressure, psi

$\mathrm{K}=$ reservoir permeability, md

$\mathrm{K}_{\mathrm{m}}=$ matrix permeability, md

$\mathrm{K}_{\mathrm{f}}$ = natural fracture permeability, md

$\varnothing=$ reservoir porosity, $\%$

$\emptyset_{\mathrm{m}}=$ matrix porosity, $\%$

$\emptyset_{\mathrm{f}}=$ natural fracture porosity, $\%$

$\mathrm{h}=$ Thickness, $\mathrm{ft}$.

$\mathrm{L}=$ Length of lateral, $\mathrm{ft}$.

$\mathrm{X}_{\mathrm{f}}=$ fracture half length, $\mathrm{ft}$

$\mathrm{W}_{\mathrm{f}}=$ hydraulic fracture width, in

$\mathrm{N}_{\mathrm{f}}=$ number of fractures

$\mathrm{P}_{\mathrm{L}}=$ Langmuir pressure, psia

$\mathrm{V}_{(\mathrm{P})}=$ gas content, $\mathrm{SCF} / \mathrm{ton}$

$\mathrm{V}_{\mathrm{L}}=$ Langmuir volume, SCF/ton

$\mathrm{L}_{\mathrm{W}}=$ Well length, $\mathrm{ft}$. 


\section{CHAPTER 1}

\section{INTRODUCTION}

Unconventional gas reservoirs such as shale gas, tight sand, and coal bed methane (CBM) has become an increasingly important source of natural gas in the United States and around the world. As a result, new technologies are being developed for gas recovery from these reservoirs. Due to very low permeability, Most of unconventional reservoirs do not produce at economic flow rates unless they are stimulated to create the conduit for the gas to flow into the well. The most common techniques used to unlock these unconventional gas resources are horizontal drilling with multi stages hydraulic fracturing.

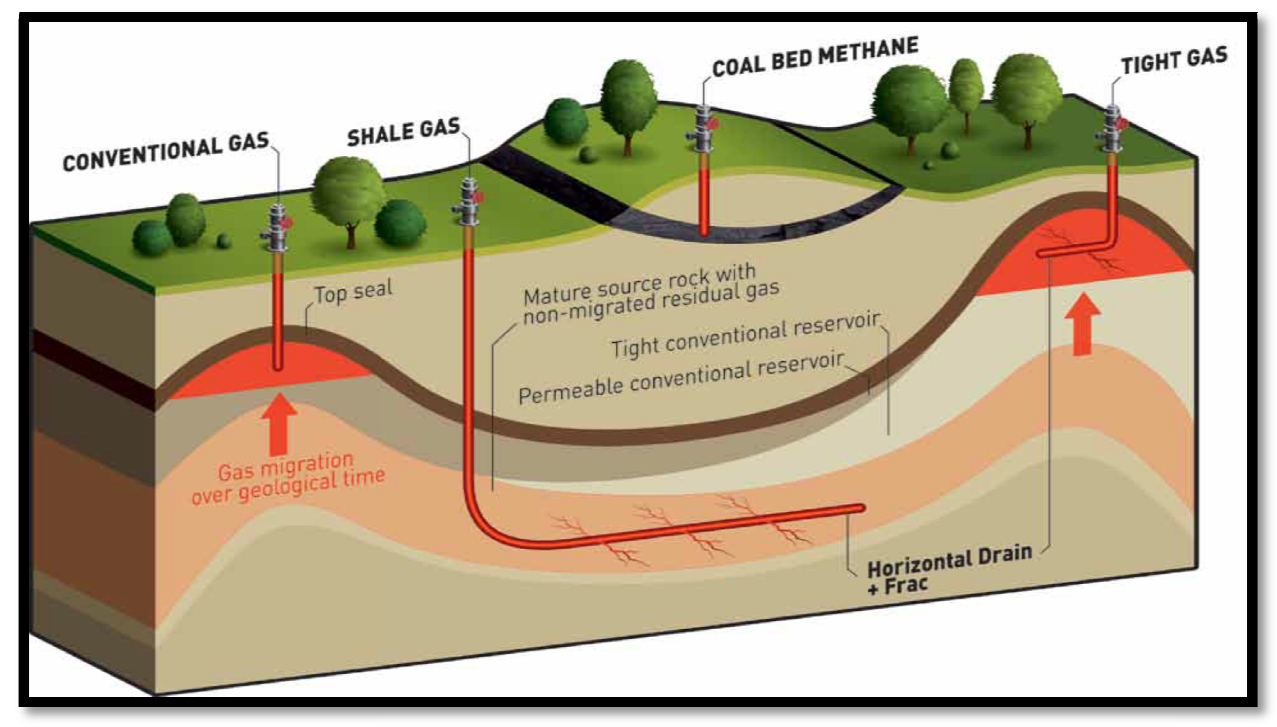

Figure 1: Unconventional gas reservoir locations (Total, 2012)

Horizontal drilling provides greater access to the gas trapped in the formation. A vertical well is first drilled to the targeted rock formation. At the objective depth, the drill bit is turned to bore a well that extends through the reservoir horizontally, exposing the well to more surface 
area in the formation. Hydraulic Fracturing is used to release the gas by opening fractures or cracks in the rock and allowing natural gas to flow from the formation to the well.

Marcellus shale is one of the most important unconventional reservoirs in United State that is believed to have trillions of cubic feet of gas in place. However, the production from Marcellus shale is new and the production data is only available for a few years. The ultimate gas recovery is an important economic parameter and it is necessary early in the life of the well to determine the economic viability. Currently no method is available for predicting the ultimate recovery based on the available limited production history. The objective of this study to establish a relationship between the ultimate gas recovery from horizontal well with multiple hydraulic fracture stages completed in Marcellus shale formation and the limited available production history. Furthermore, the effect of the reservoir and fracture properties on the gas recovery will be investigated to identify the key parameters that influence the relationship. 


\section{CHAPTER 2}

\section{LITERATURE AND REVIEW}

\section{Marcellus Shale}

Figure 2 illustrates the extent of the Marcellus shale. Marcellus shale is low permeability black shale that contains largely untapped natural gas resources; this makes Marcellus shale an attractive target for energy development.

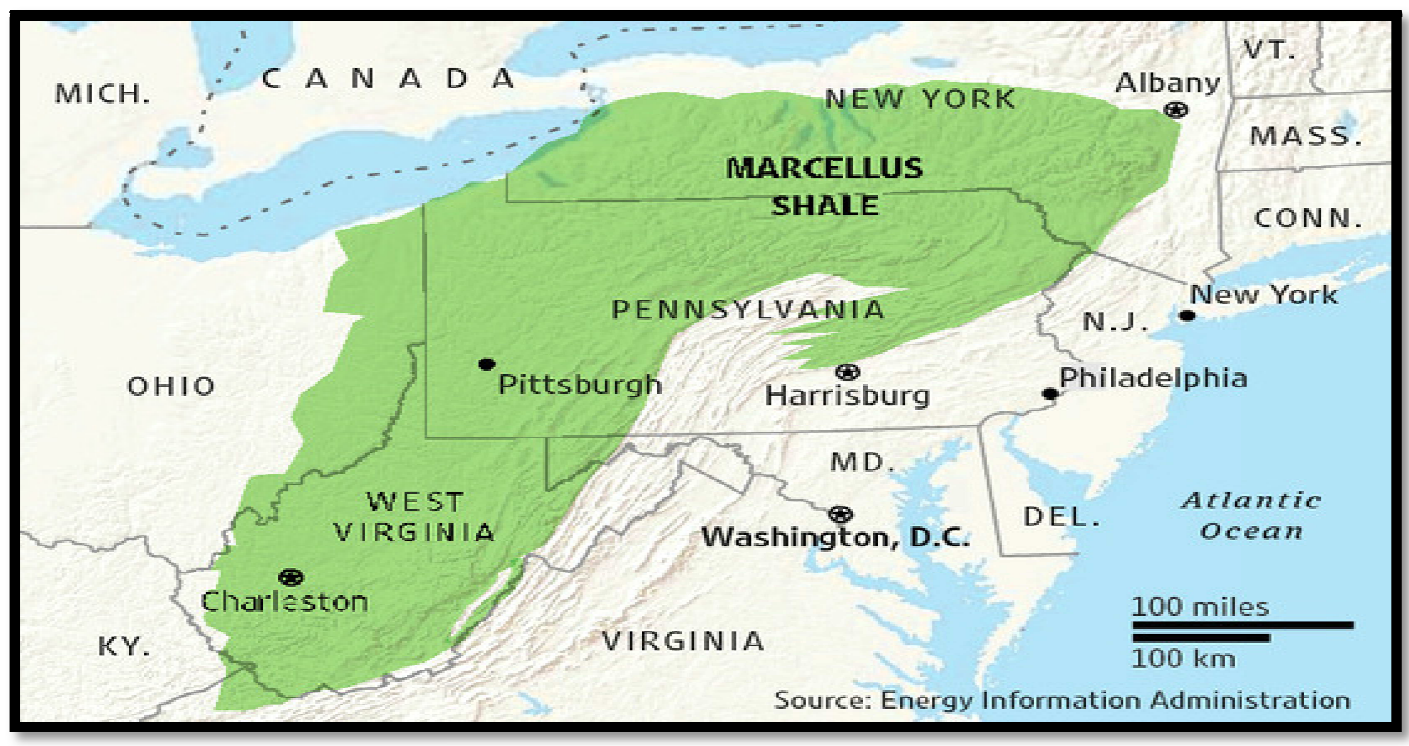

Figure 2: Distribution of the Marcellus Shale Formation (The Wall Street Journal, 2011)

The depth of Marcellus shale ranges from 4000 to 8000 feet with 1500 TCF gas-in-place estimated (USDOE, 2009). However, the estimate of recoverable natural varies significantly. The United States Geological Survey (USGS) reported in 2011 that the Marcellus shale is estimated to have 84 TCF of natural gas while the US Energy Information Administration (EIA, 2011) claimed the recoverable gas reserve is approximately 400 TCF. In 2009, Dr. Terry Engelder, Penn State geologist, stated that Marcellus contain 489 TCF of recoverable gas. These differences can be 
attributed to different models and assumptions that were used to estimate the recoverable natural gas from Marcellus shale.

In shale formation, the gas can be stored as adsorbed gas on the surface of shale and free gas in matrix pores and natural fractures. Hence, shale gas reservoirs are more accurately characterizes by dual porosity model than single porosity model.

\section{Dual-porosity Model}

Dual porosity models represent natural fracture porosity and matrix reservoir porosity, shale formations often characterize as dual porosity. In dual porosity there is interaction between the natural fractures and rock matrix in the reservoir and fluid exists in two interconnected systems, the dual porosity and how it is represented by the model shows in Figure 3.

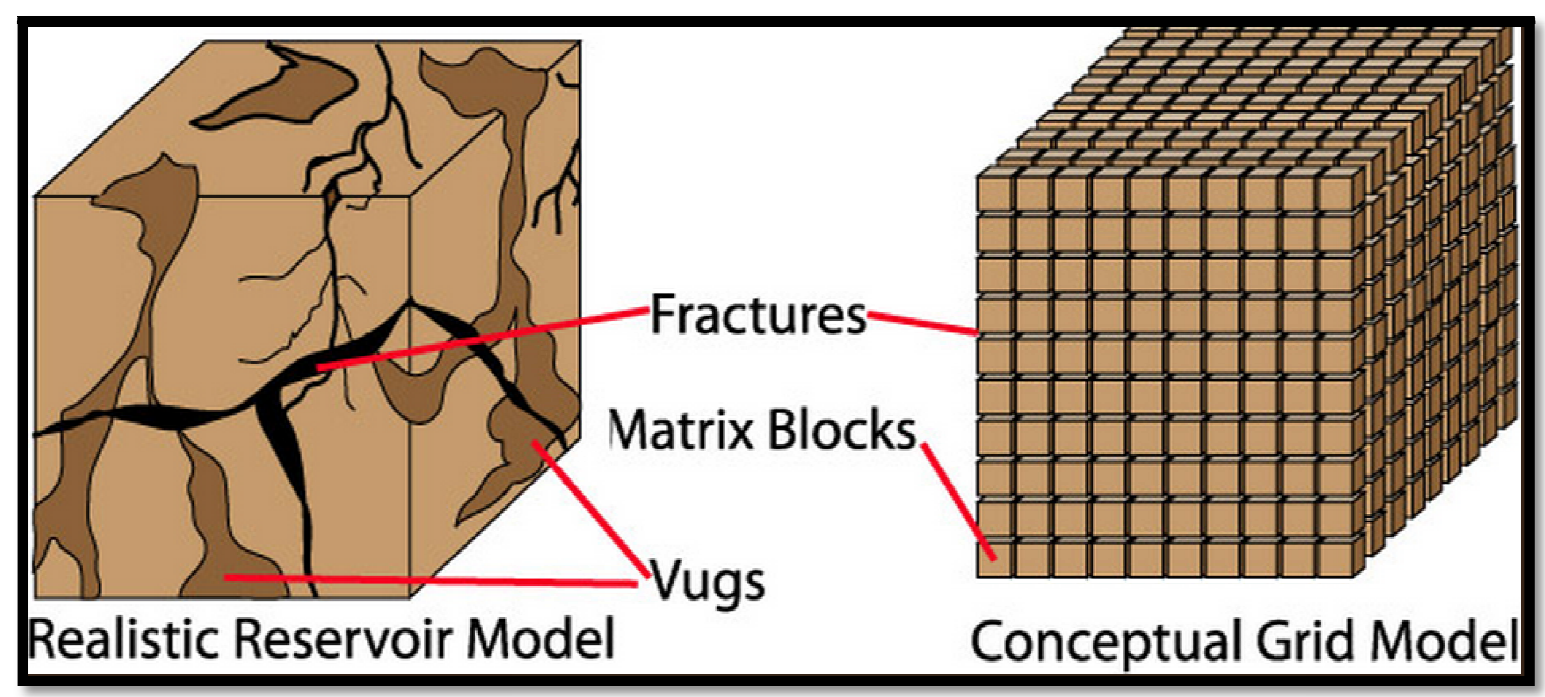

Figure 3: Dual porosity as represented by the model (Grid block, www.dcs.gla.ac.uk, 2012)

Natural fractures act as a transport medium from the matrix interior to the wellbore. The volume of gas stored within the matrix is usually much than is stored in the natural fracture. 
Because the natural fracture has high permeability, the fluid starts travelling first from the fracture to the wellbore. Once the natural fractures have been drained, the gas inside reservoir matrix which is the largest volume begins to flow toward the wellbore across the natural fracture.

\section{Gas Adsorption}

Gas adsorption is an important parameter for shale gas reservoir in order to that most of models take the description of gas adsorption in their consideration. Langmuir equation describes the gas adsorption capacity of rock as pressure changes under isothermal conditions.

Langmuir's Equation:

$$
V(P)=\frac{V_{L} P}{P_{L}+P}
$$

$\mathrm{V}(\mathrm{P})=$ Gas Content, scf/ton

$\mathrm{VL}=$ Langmuir Volume, scf/ton

$\mathrm{PL}=$ Langmuir Pressure, psia

$\mathrm{P}=$ Pressure, $\mathrm{psi}$

VL is the maximum amount of gas that can be adsorbed on the shale at infinite pressure, PL affects the curvature of the isotherm and corresponds to the pressure at which half of the Langmuir volume is adsorbed. Langmuir Isotherm curve showed in Figure 4. 


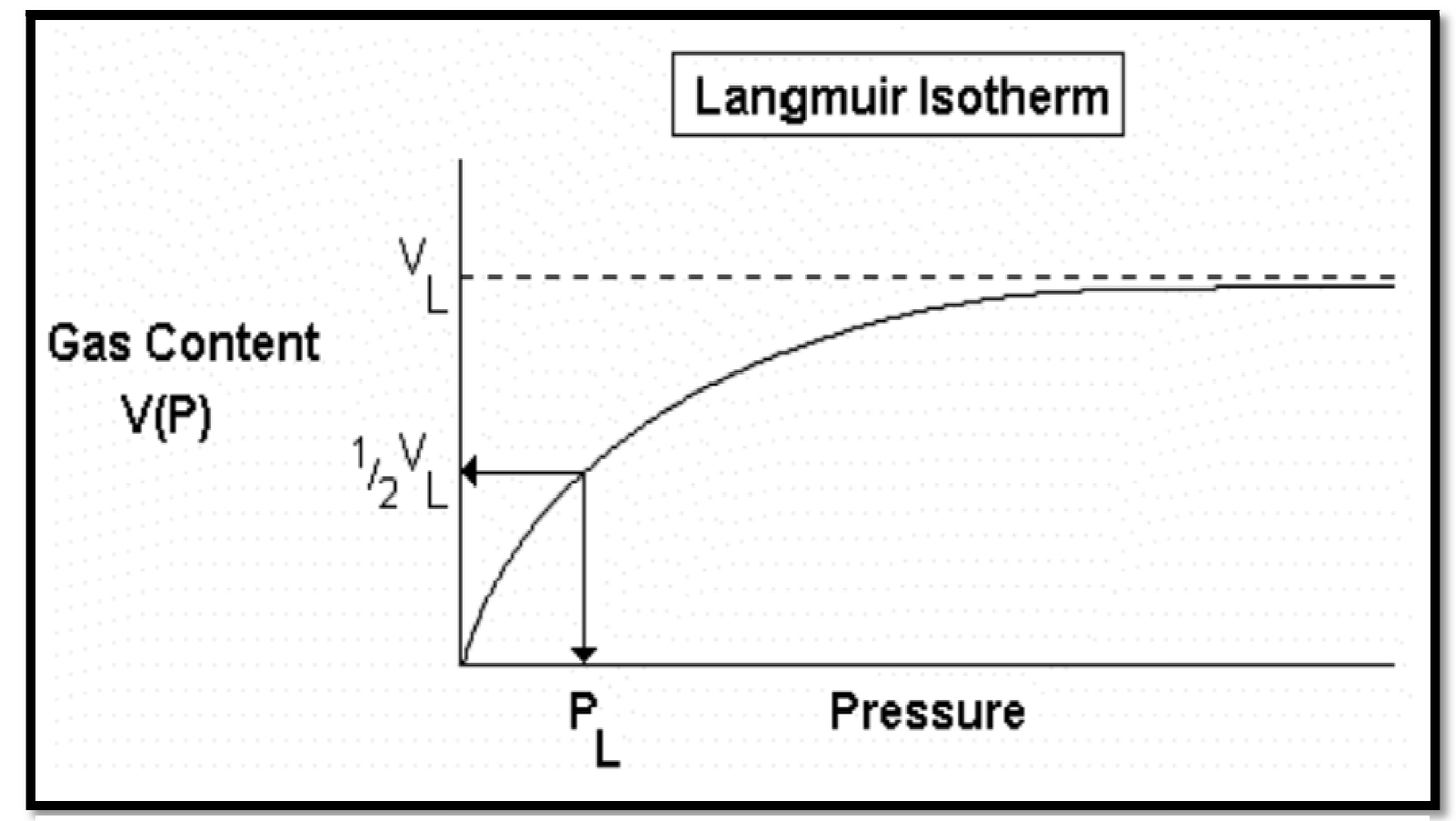

Figure 4: Langmuir Isotherm (Reservoir, www.fekete.com)

\section{Production Technologies in shale gas reservoirs}

In order to economically produce the shale gas reservoirs, which have low natural permeability, it is necessary to drill horizontal wells and complete with multi stages (hydraulic fracturing).

Horizontal wells are common used in low permeability reservoirs and have been successfully applied in shale gas. Horizontal drilling with multiple hydraulic fracturing is recognized as the key technology for economically extracting gas from the shale formations. In addition, horizontal wells and the induced hydraulic fractures expose more reservoir rock to the wellbore and intersect more of the natural fractures (fissures). 


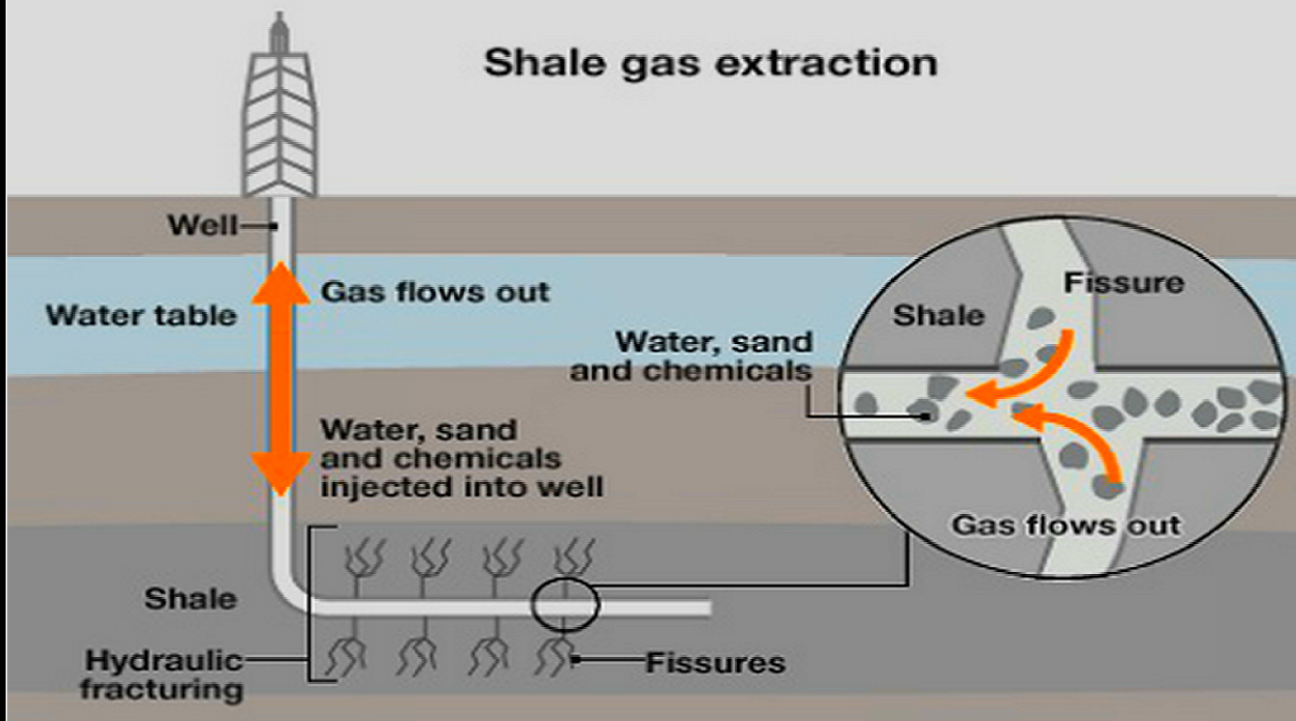

Figure 5: Horizontal well with multiple hydraulic fractures (Shale gas diagram, www.ChartDiagram.com, 2013)

This technique is very efficient for development of unconventional reservoir such as shale gas. Hydraulic fracturing is believed to create, a fracture network as illustrated in Figure 5 which is a major factor in enhancing the fluid flow to the wellbore. The larger the created fracture networks are, the higher would the well productivity. 


\section{CHAPTER 3 \\ OBJECTIVE AND METHODOLOGY}

The objective of this study is to predict the ultimate gas recovery from a Marcellus shale reservoir based on the early production.

The following steps were employed to achieve the objectives:

1. A base model was developed based on the Field data from horizontal well producing from Marcellus shale formation.

2. The base model was used to simulate the 30-year production histories using 7, 13 and 17 hydraulic fracture stages and different fractures half length $350,500,650 \mathrm{ft}$.

3. The ratio of the 1,2 and 3-year cumulative production to 30-year cumulative production was determined for each case.

4. The impacts of rock properties, number of hydraulic fracture stages and fracture half length on the ratio were investigated.

5. Correlations were developed to predict the ratio based on reservoir and hydraulic fracture properties.

6. A case study was performed to evaluate the reliability of the correlation.

\section{Base Model Development}

Eclipse reservoir simulation software was used to develop a numerical reservoir model. The simulator was used to model a horizontal well with multiple stages hydraulic fractures 7,13 and 17 stages. The model was designed with 5 layers. The drainage was assumed to be $4000 \mathrm{ft} x$ 
$2000 \mathrm{ft}$ and the horizontal well, 3000 feet long, was placed at the center of the reservoir as illustrated in Figure 6.

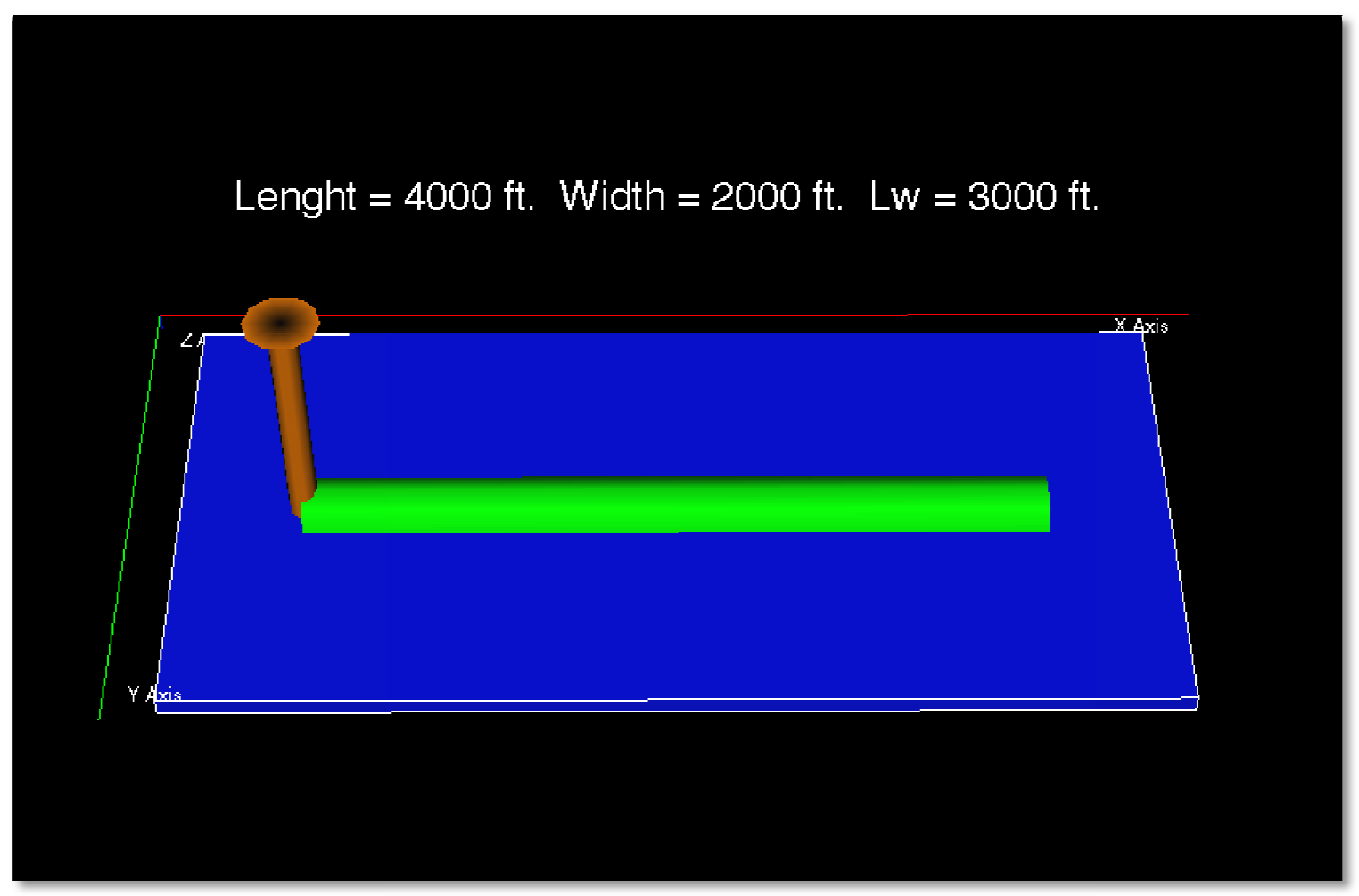

Figure 6: A horizontal well model with a $4,000 \mathrm{ft}$ by $2,000 \mathrm{ft}$ and well length of $3,000 \mathrm{ft}$

The values of the parameters in the base model are summarized in Table 1. While the values that were changed to study their impact on the recovery ratio are showed in Table 2. 
Table 1: Parameters and values used in the base model

\begin{tabular}{|c|c|}
\hline Parameter & \\
\hline Depth, ft. & 7000 \\
\hline Reservoir length, ft. & 4,000 \\
\hline Reservoir width, ft. & 2,000 \\
\hline Thickness, ft. & 75 \\
\hline Horizontal well length, ft. & 3,000 \\
\hline Area, Acres & 183.90805 \\
\hline \multicolumn{2}{|l|}{ Rock Properties } \\
\hline Model & Dual Porosity \\
\hline Matrix porosity, fraction & 0.05 \\
\hline $\mathrm{x}$-direction Matrix Permeability (md) & 0.0002 \\
\hline y-direction Matrix Permeability (md) & 0.0002 \\
\hline z-direction Matrix Permeability (md) & 0.00002 \\
\hline Fracture porosity, fraction & 0.005 \\
\hline $\mathrm{x}$-direction Fracture Permeability (md) & 0.004 \\
\hline y-direction Fracture Permeability (md) & 0.004 \\
\hline z-direction Fracture Permeability (md) & 0.0004 \\
\hline Rock Density, lb/ft ${ }^{3}$ & 100 \\
\hline Matrix Fracture (Sigma), $1 / \mathrm{ft}^{2}$ & 0.073 \\
\hline \multicolumn{2}{|l|}{ Initial Conditions } \\
\hline Reservoir pressure, psia & 3000 \\
\hline Water saturation, fraction & 0.15 \\
\hline \multicolumn{2}{|l|}{ Hydraulic Fracture Properties } \\
\hline Number of hydraulic fracture, stages & 7 \\
\hline Fracture half length, ft. & 500 \\
\hline Width, in. & 0.01 \\
\hline Top of Fracture, ft. & 7,000 \\
\hline Bottom of Fracture, ft. & 7075 \\
\hline Permeability, md & 10,000 \\
\hline Porosity, fraction & 0.1 \\
\hline \multicolumn{2}{|l|}{ Well Production Controls } \\
\hline Pwf, psia & 500 \\
\hline \multicolumn{2}{|l|}{ Fluid Properties } \\
\hline Standard pressure, psia & 14.7 \\
\hline Standard temperature, ${ }^{\circ} \mathrm{F}$ & 60 \\
\hline Reference temperature, ${ }^{\circ} \mathrm{F}$ & 120 \\
\hline \multicolumn{2}{|l|}{ Adsorption Parameters } \\
\hline Langmuir Pressure, psia & 635 \\
\hline Langmuir Concentration, Mscf/ton & 0.089 \\
\hline
\end{tabular}


Table 2: The values used in the model

\begin{tabular}{|l|c|c|}
\hline \multicolumn{1}{|c|}{ Parameters } & Range & The Values \\
\hline Number of Hydraulic fracture, stages & $\mathbf{7 - 1 7}$ & 7,13 \& 17 \\
\hline Fracture half length, ft & $\mathbf{3 5 0 - 6 5 0}$ & $350,500 \& 650$ \\
\hline Matrix porosity, fraction & $\mathbf{0 . 0 3 - 0 . 0 7}$ & $0.03,0.04,0.05,0.06 \& 0.07$ \\
\hline X-direction Matrix Permeability (md) & $\mathbf{0 . 0 0 0 2 - 0 . 0 0 3}$ & $0.0002,0.001 \& 0.003$ \\
\hline Y-direction Matrix Permeability (md) & $\mathbf{0 . 0 0 0 2 - 0 . 0 0 3}$ & $0.0002,0.001 \& 0.003$ \\
\hline Z-direction Matrix Permeability (md) & $\mathbf{0 . 0 0 0 0 2 - 0 . 0 0 0 3}$ & $0.00002,0.0001 \& 0.0003$ \\
\hline Fracture porosity, fraction & $\mathbf{0 . 0 2 - 0 . 0 6}$ & $0.002,0.004,0.005 \& 0.006$ \\
\hline X-direction Fracture Permeability (md) & $\mathbf{0 . 0 0 2 - 0 . 0 0 5}$ & $0.002,0.003,0.004 \& 0.005$ \\
\hline Y-direction Fracture Permeability (md) & $\mathbf{0 . 0 0 2 - 0 . 0 0 5}$ & $0.002,0.003,0.004 \& 0.005$ \\
\hline Z-direction Fracture Permeability (md) & $\mathbf{0 . 0 0 0 2 - 0 . 0 0 0 5}$ & $0.0002,0.0003,0.0004 \& 0.0005$ \\
\hline
\end{tabular}

\section{Model Parameters and Assumptions}

In order to investigate the impact of different reservoir and fracture parameters on the recovery ratio, a number of cases were created from the base model by changing one of the parameters while keeping the other parameters constant. The impact of the following parameters was investigated:-

\section{Number of Hydraulic fracture stages:}

The base model assumes that the horizontal well is hydraulically fractured in multiple stages. The number of stages was assumed to be 7,13 , and 17 for different cases. 


\section{Fracture half length $\left(\mathbf{X}_{\mathbf{f}}\right)$ :}

In order to examine the effect of fracture half length on the recovery ratio, three values of fracture half length were used $350 \mathrm{ft}$., $500 \mathrm{ft}$. and $650 \mathrm{ft}$.

\section{Matrix porosity $\left(\emptyset_{\mathrm{m}}\right)$ :}

To study the impact of matrix porosity on the recovery ratio, values of $0.03,0.04,0.05$, 0.06 , and 0.07 were assigned to the matrix porosity in the model. The matrix porosity in the base model was 0.05 . This case used for different numbers of hydraulic fractures 7,13 and 17 stages.

\section{Matrix permeability $\left(K_{m}\right)$ :}

Different values of Matrix permeability in $\mathrm{x}, \mathrm{y}, \mathrm{z}$ directions were used in this study. The permeability for the matrix in the base case was $0.0002 \mathrm{md}$ in $\mathrm{x}$ and $\mathrm{y}$ directions and $0.00002 \mathrm{md}$ in $\mathrm{z}$ direction.

Natural fracture porosity $\left(\varnothing_{\mathrm{f}}\right)$ :

The fracture porosity was considered 0.005 in the base case. It changed to $0.002,0.004$ and 0.006 to investigate the impact.

\section{Natural fracture permeability $\left(K_{\mathbf{f}}\right)$ :}

The impact of the fracture permeability on the recovery ratio was studied for different values in each direction $\mathrm{x}, \mathrm{y}$, and $\mathrm{z}$. The values were $0.002,0.003,0.005$ and $0.006 \mathrm{md}$ in $\mathrm{x}$ and $\mathrm{y}$ directions, however in $\mathrm{z}$ directions were $0.0002,0.0003,0.0005$ and $0.0006 \mathrm{md}$. 


\section{CHAPTER 4 RESULTS AND DISCUSSIONS}

In this chapter, the results from the simulation runs are presented with discussion the impact of the early production, the fracture half lengths, the number of stages and the rock properties on the gas recovery ratio. Thirty years of production data with cases for $350,500,650$ ft. fractures half lengths were run in commercial reservoir simulation and 7, 13, 17 stage stimulation stages equally spaced in $3000 \mathrm{ft}$ lateral were used in each fracture half length. In each stage with different fracture half lengths, the rock properties were changed to various numbers. A correlation was established to predict the recovery ratio using initial production duration (1-3 years).

To estimate the recovery ratio from the early production data, the impact of different parameters on the ratio was investigated. These parameters are rock properties, number of fractures and fracture half length.

\section{The Impact of Rock Properties:}

Matrix permeability $\left(K_{m}\right)$ and Fracture porosity $\left(\emptyset_{f}\right)$ Impact

Natural fracture porosity and matrix permeability have no impacts on the gas recovery ratio in all cases as showed in Figure 7 through 12 because the fracture porosity has low storage capacity and the matrix permeability is a very low. The values used for different case are given in Table 3. 
Table 3: Used values for fracture porosity and matrix permeability

\begin{tabular}{|l|c|}
\hline \multicolumn{1}{|c|}{ Parameters } & Used Values \\
\hline Fracture porosity, fraction & $0.002,0.004,0.005 \& 0.006$ \\
\hline Matrix Permeability X-direction, (md) & $0.0002,0.001 \& 0.003$ \\
\hline Matrix Permeability Y-direction, (md) & $0.0002,0.001 \& 0.003$ \\
\hline Matrix Permeability Z-direction, (md) & $0.00002,0.0001 \& 0.0003$ \\
\hline
\end{tabular}

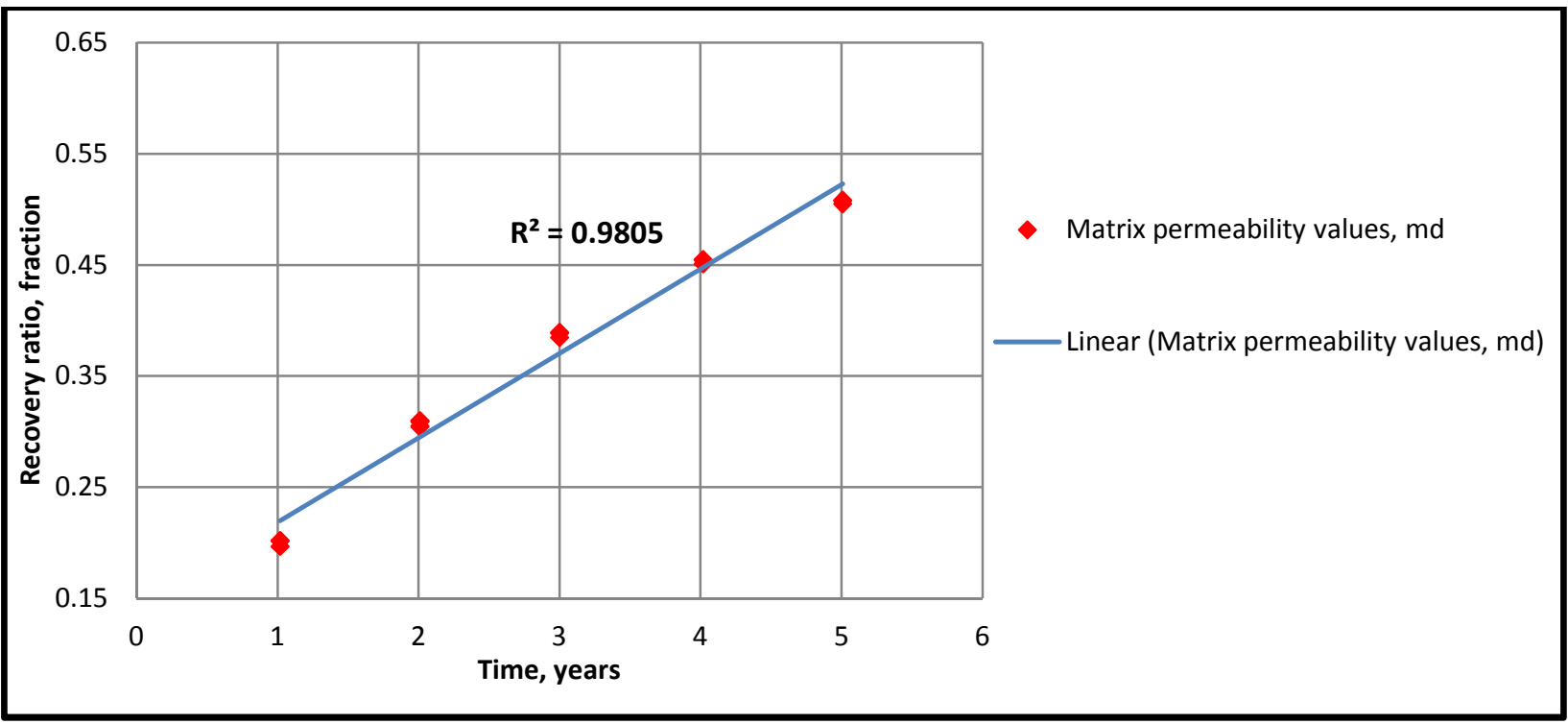

Figure 7: Impact matrix permeability on the recovery ratio for, 7-stage hydraulic fracture

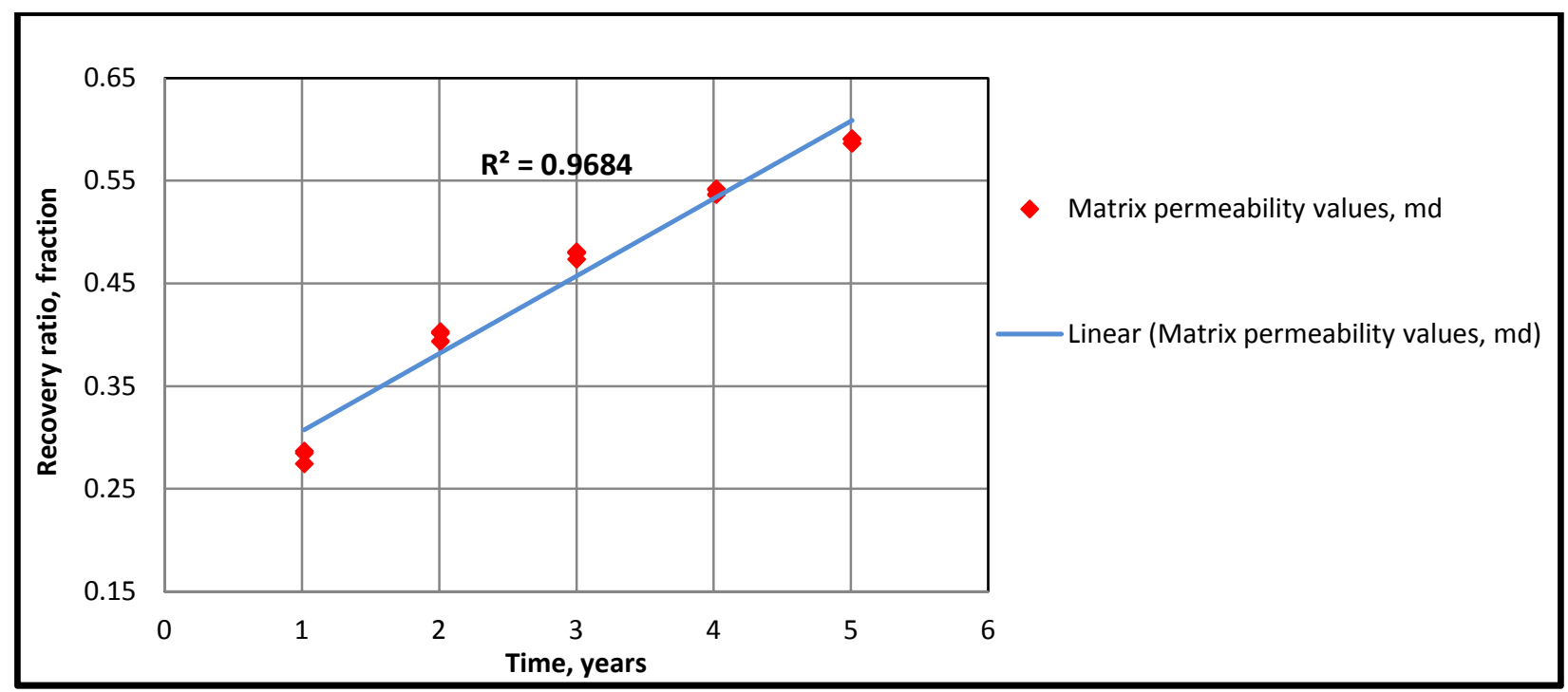

Figure 8: Impact matrix permeability on recovery ratio for 13-stage hydraulic fracture 


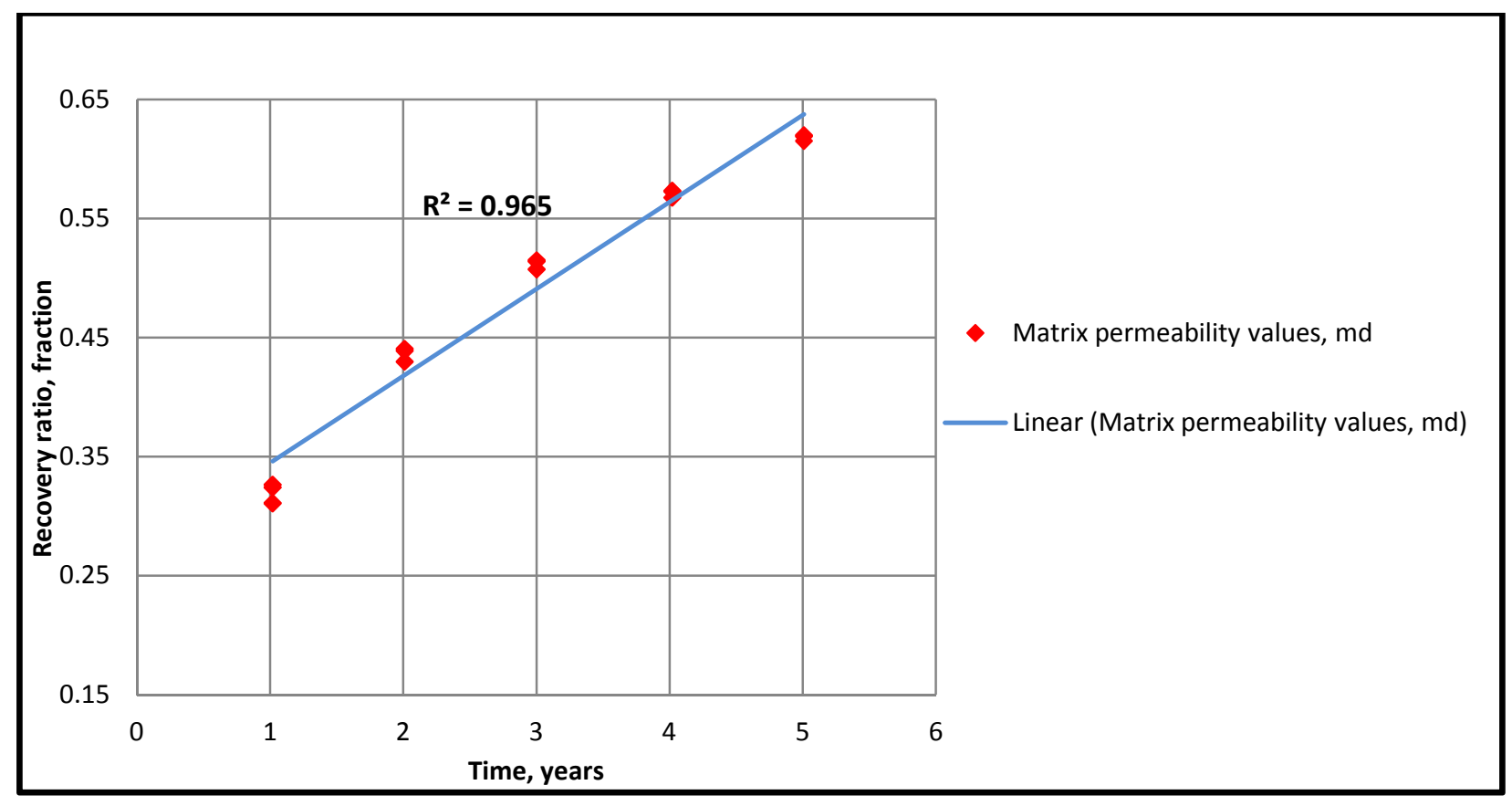

Figure 9: Impact matrix permeability on recovery ratio for 17-stage hydraulic fracture

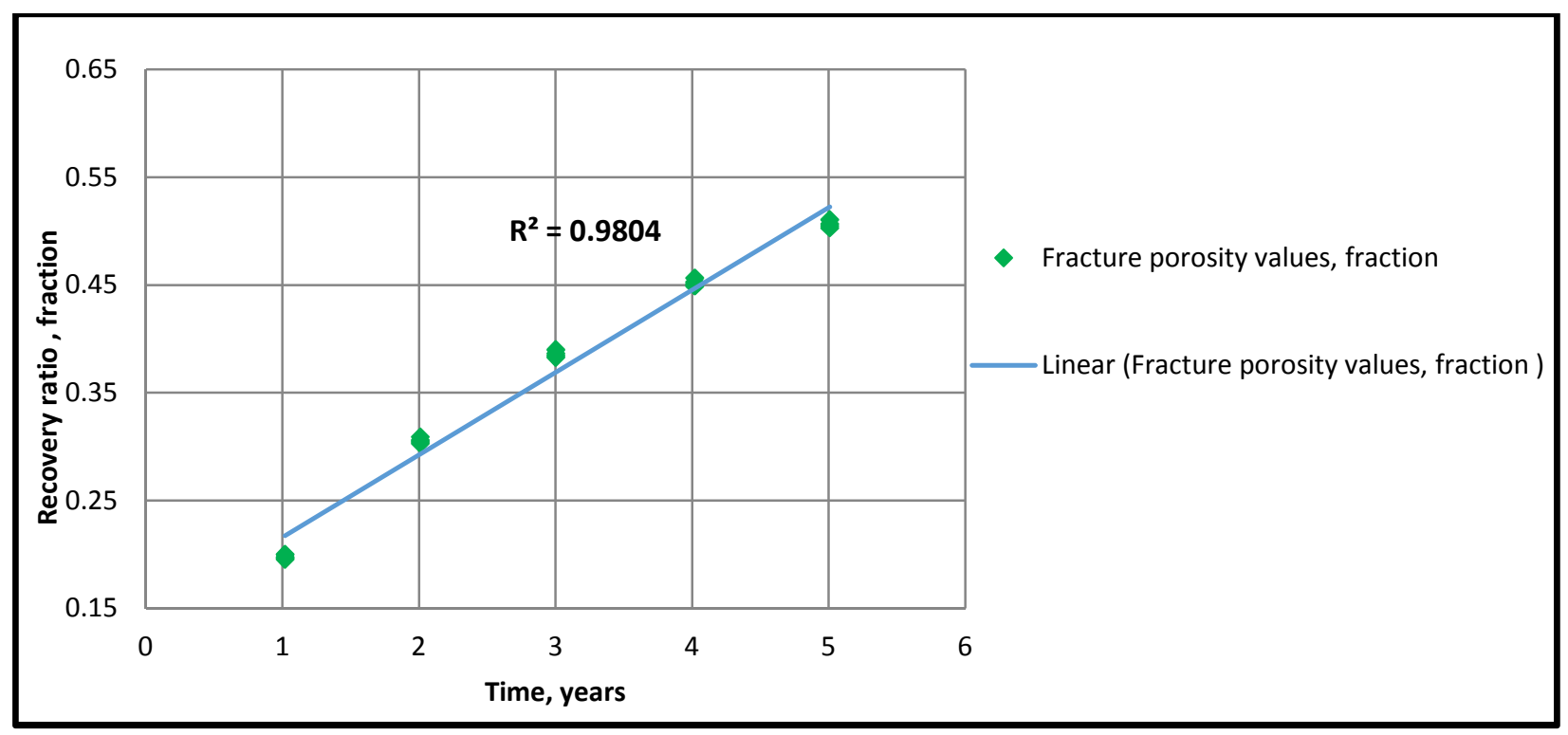

Figure 10: Impact natural fracture porosity on recovery ratio for 7 stage hydraulic fracture 


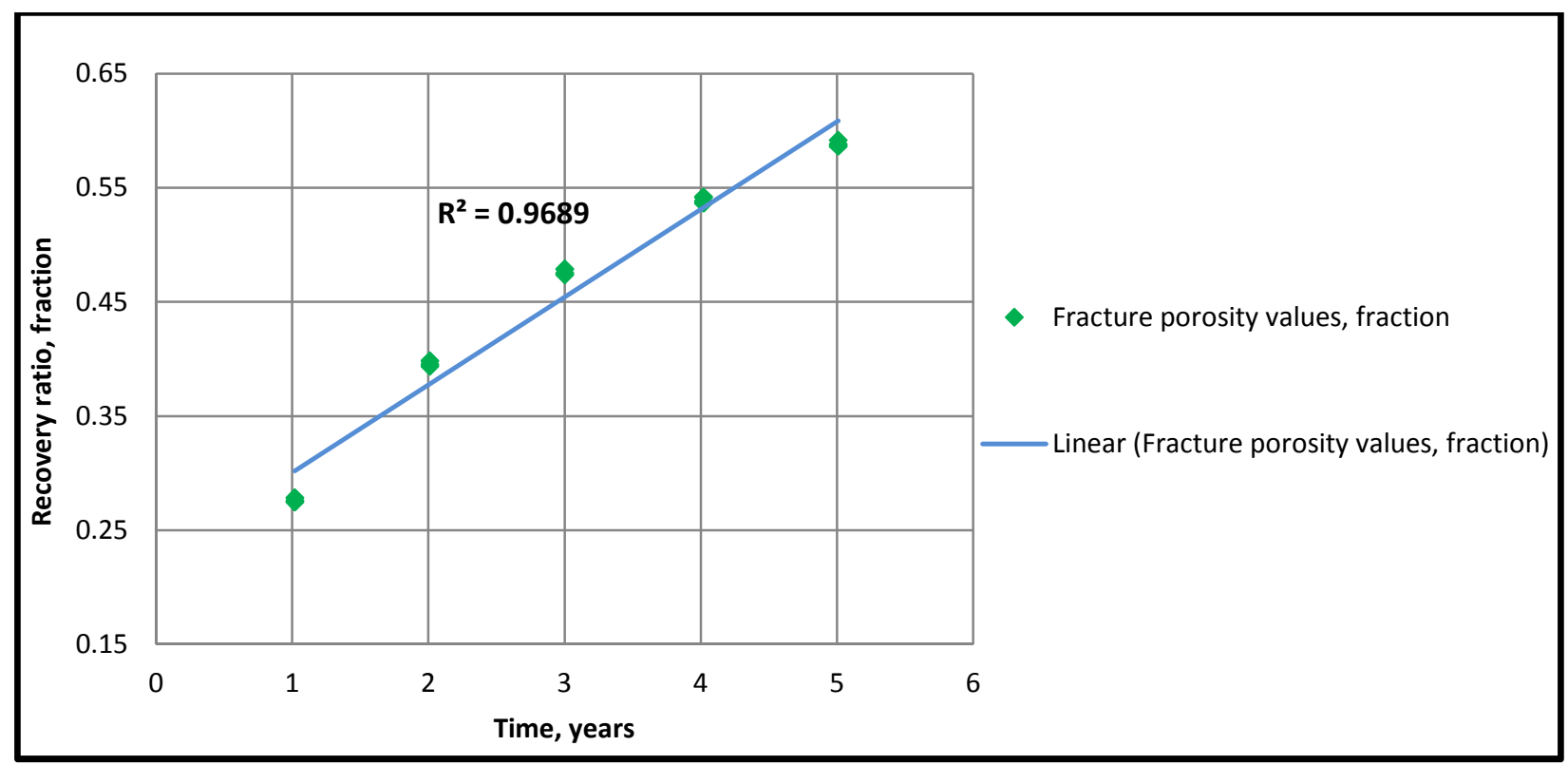

Figure 11: Impact natural fracture porosity on recovery ratio for 13-stage hydraulic fracture

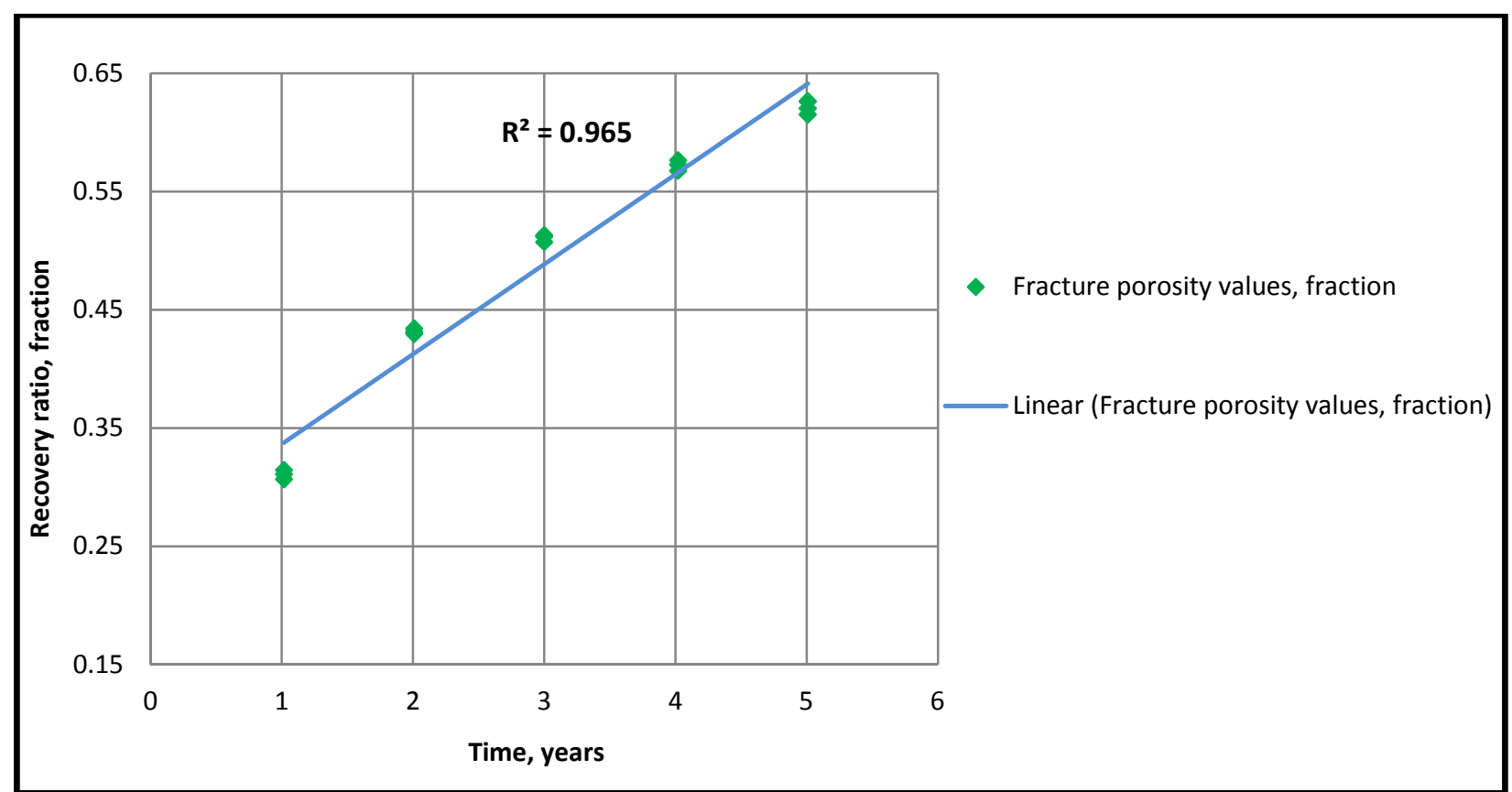

Figure 12: Impact natural fracture porosity on recovery ratio for 17-stage hydraulic fracture 


\section{Fracture permeability $\left(\mathrm{K}_{\mathrm{f}}\right)$ Impact}

Natural fracture permeability was found to have an insignificant impact on the gas recovery ratio. The values of natural fracture permeability are showing in Table 4.

Table 4: Used values for fracture permeability

\begin{tabular}{|c|c|}
\hline Parameters & Values Used \\
\hline Fracture Permeability X-direction, (md) & $0.002,0.003,0.004 \& 0.005$ \\
\hline Fracture Permeability Y-direction, (md) & $0.002,0.003,0.004 \& 0.005$ \\
\hline Fracture Permeability Z-direction, (md) & $0.0002,0.0003,0.0004 \& 0.0005$ \\
\hline
\end{tabular}

Figurers 13 to 15 illustrate the impact of natural fracture permeability on the ratio when the numbers of fracture stages are 7,13 and 17 respectively. As can be noted, the fracture permeability has a minor impact on the recovery ratio.

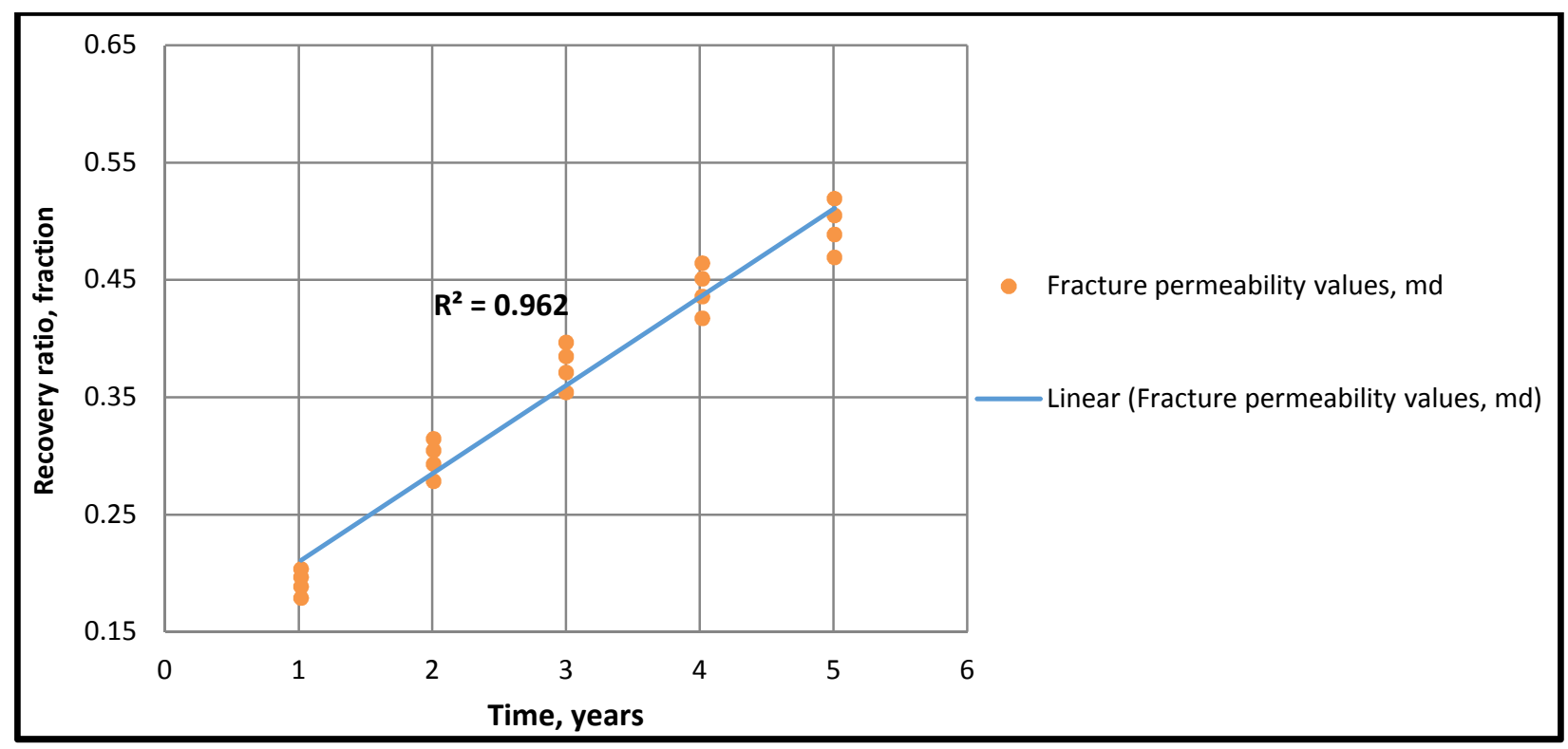

Figure 13: Impact natural fracture permeability on recovery ratio for 7-stage hydraulic fracture 


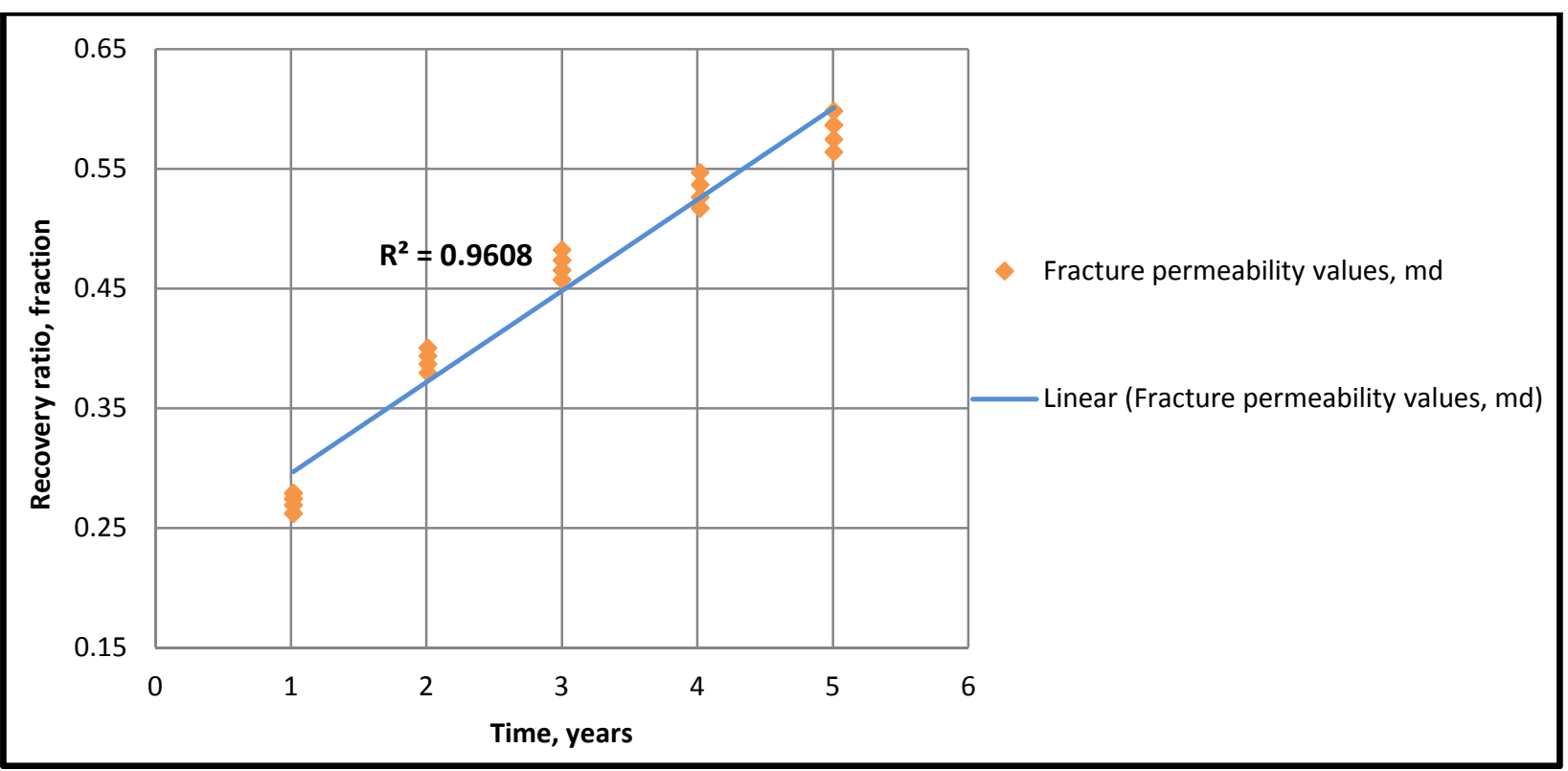

Figure 14: Impact natural fracture permeability on recovery ratio for 13-stage hydraulic fracture

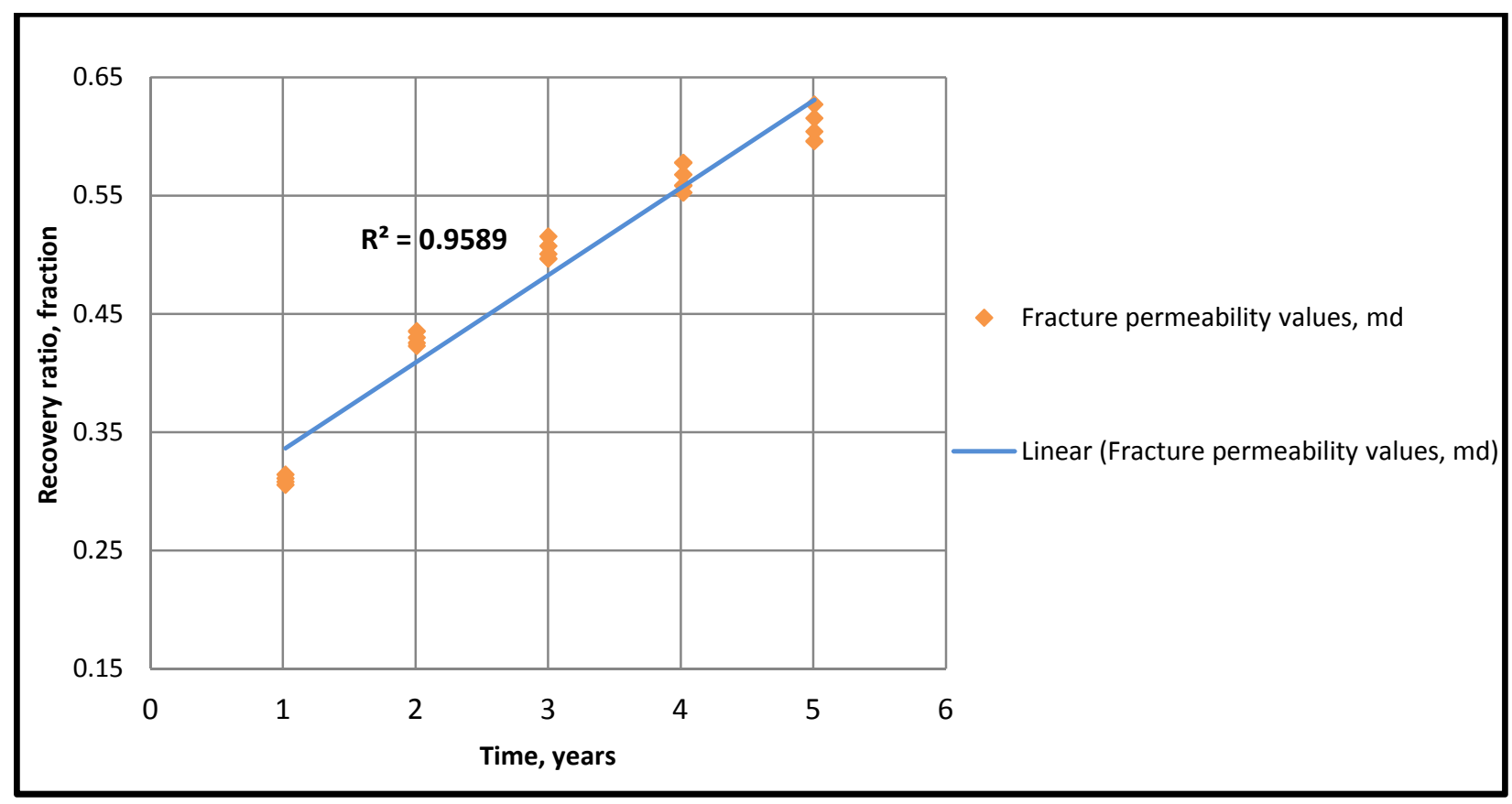

Figure 15: Impact natural fracture permeability on recovery ratio for 17-stage hydraulic fracture 


\section{Matrix porosity $\left(\emptyset_{m}\right)$ Impact}

Reservoir Matrix porosity has a significant impact on the gas recovery ratio, it was changed for different values which are illustrated in Table 5. As can be seen, in Figure 16 to 18 the recovery ratio increases as the matrix porosity is decreased while the recovery ratio increase improves as the number of hydraulic fractures is increased. The equations in the charts explain the linear regression for each $\left(\emptyset_{\mathrm{m}}\right)$ value, the $\mathbf{X}$ coefficient for each equation represents the rate of recovery ratio increase per year. The values for coefficients are different. This mean the matrix porosity has mainly impact on the ratio.

Table 5: Used value for matrix porosity

\begin{tabular}{|c|c|}
\hline Parameters & Values Used \\
\hline Matrix porosity, fraction & $0.03,0.04,0.05,0.06 \& 0.07$ \\
\hline
\end{tabular}

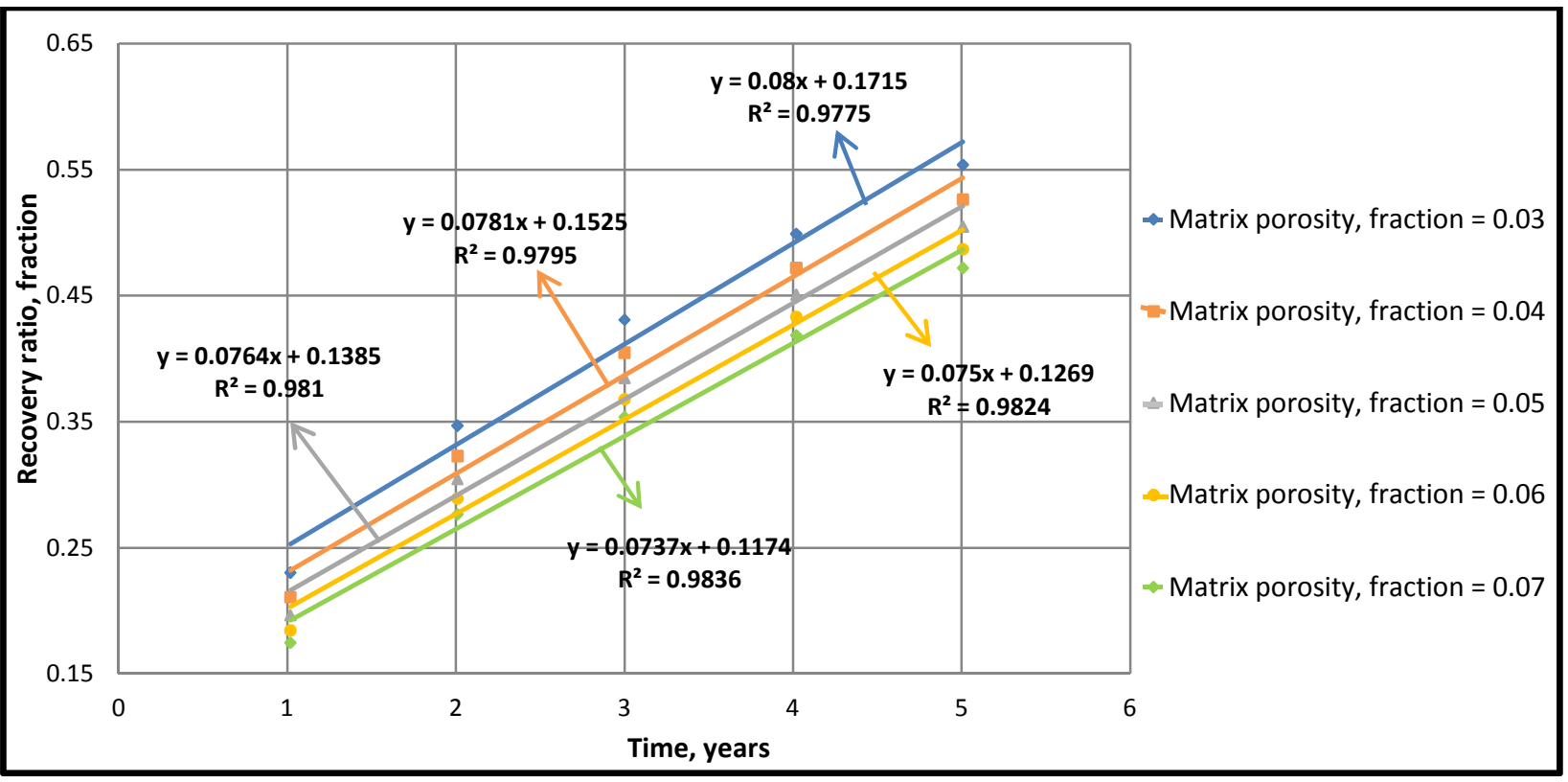

Figure 16: Impact matrix porosity on recovery ratio for 7-stage hydraulic fracture 


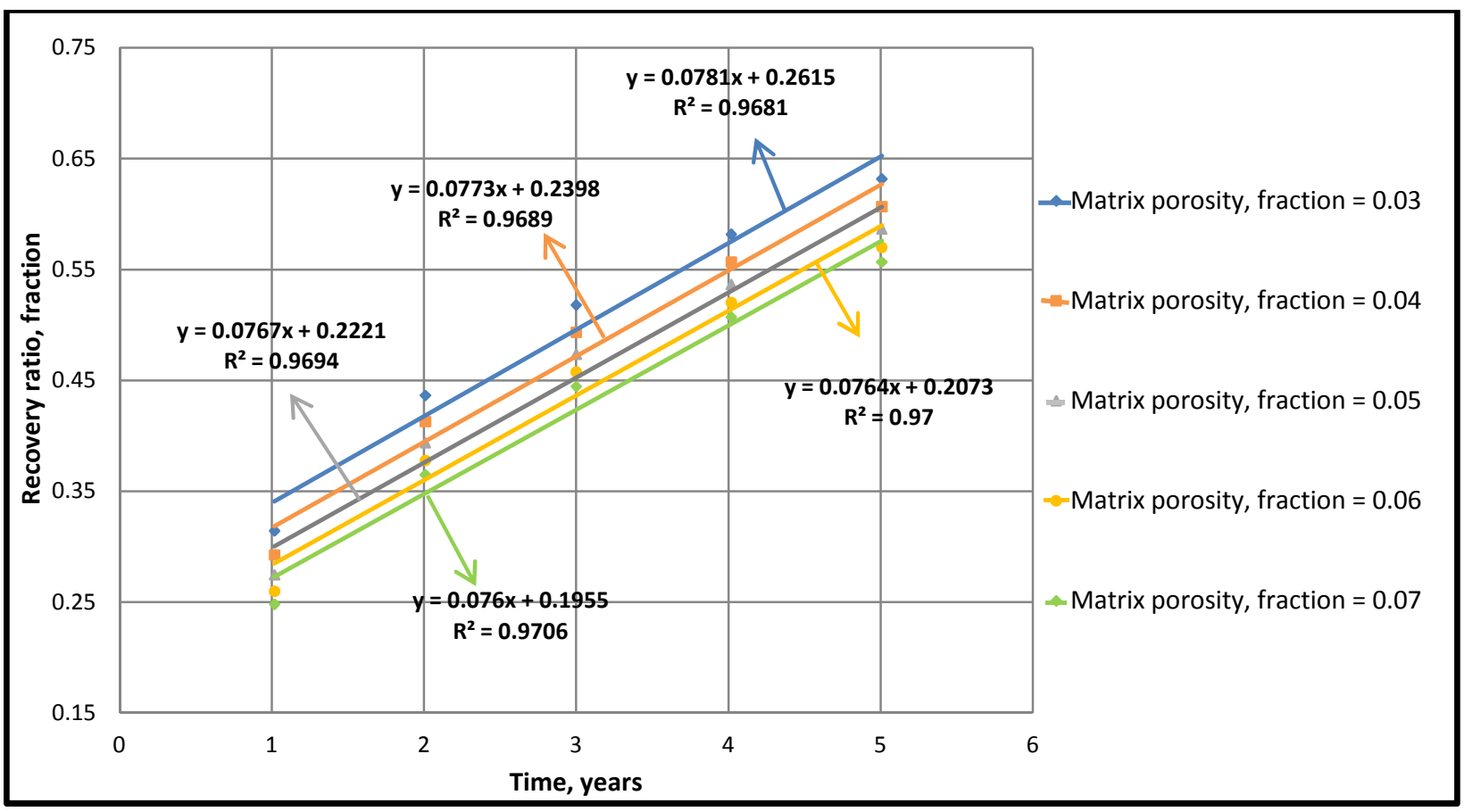

Figure 17: Impact matrix porosity on recovery ratio for 13-stage hydraulic fracture

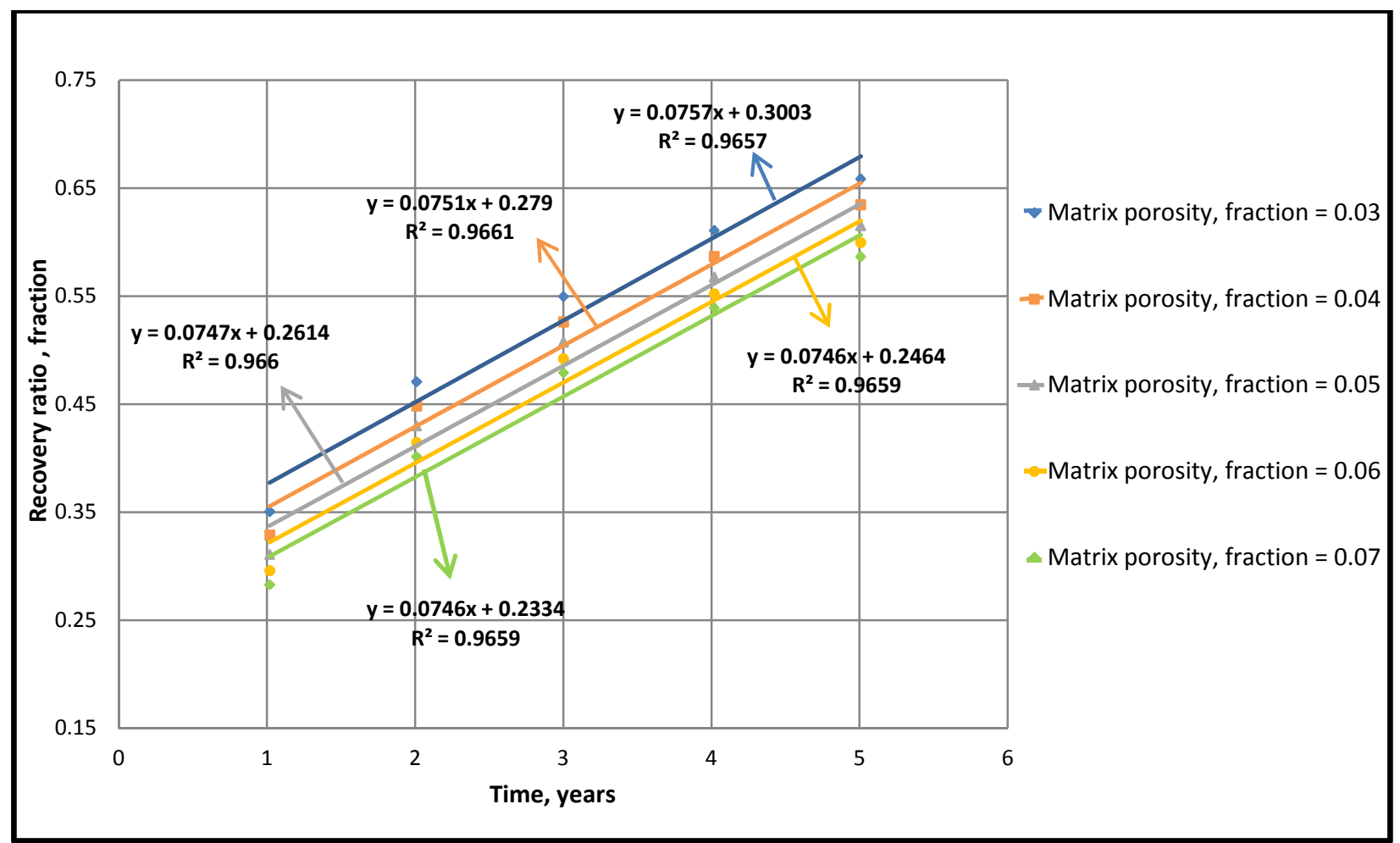

Figure 18: Impact matrix porosity on recovery ratio for 17-stage hydraulic fracture 


\section{The Impact of Number of Hydraulic Fractures}

Since the other rock properties do not have significant impact on the recovery ratio, the impact of number of hydraulic fractures with the reservoir matrix porosity was investigated. Figure 19 shows the recovery ratio increase as the numbers of hydraulic fracture are increased to 7, 13 and 17 stages. The spaces between fractures are equally divided and the fractures are parallel with each other. As it can be observed, the recovery ratio increase improves as the values of matrix porosity are decreased.

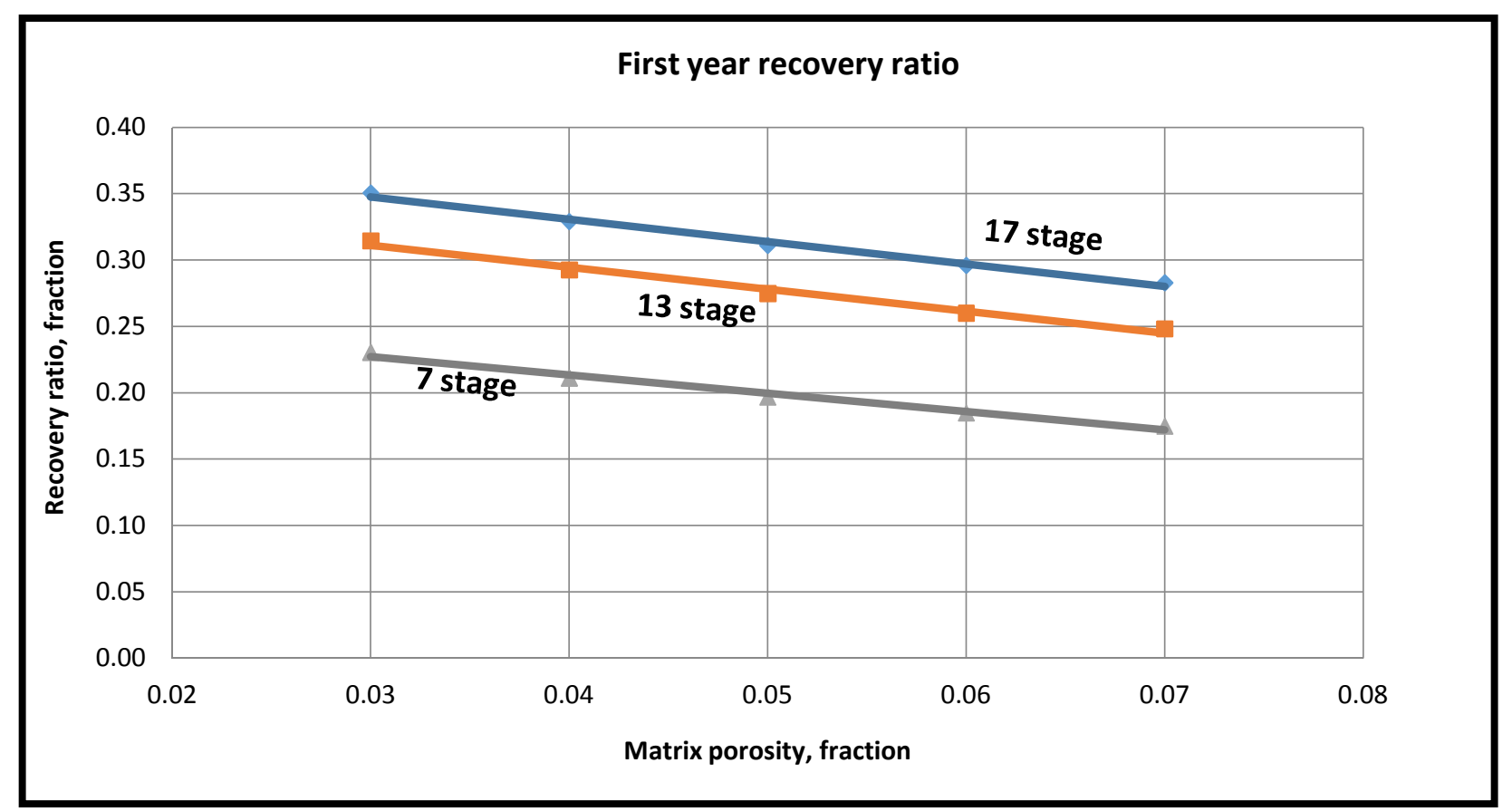

Figure 19: Impact the number of fractures on the recovery ratio based on $1^{\text {st }}$ year production

As can be seen in Figure 20 and 21, the recovery ratio increases for 7, 13 and 17 hydraulic fractures with the second and third year production. 


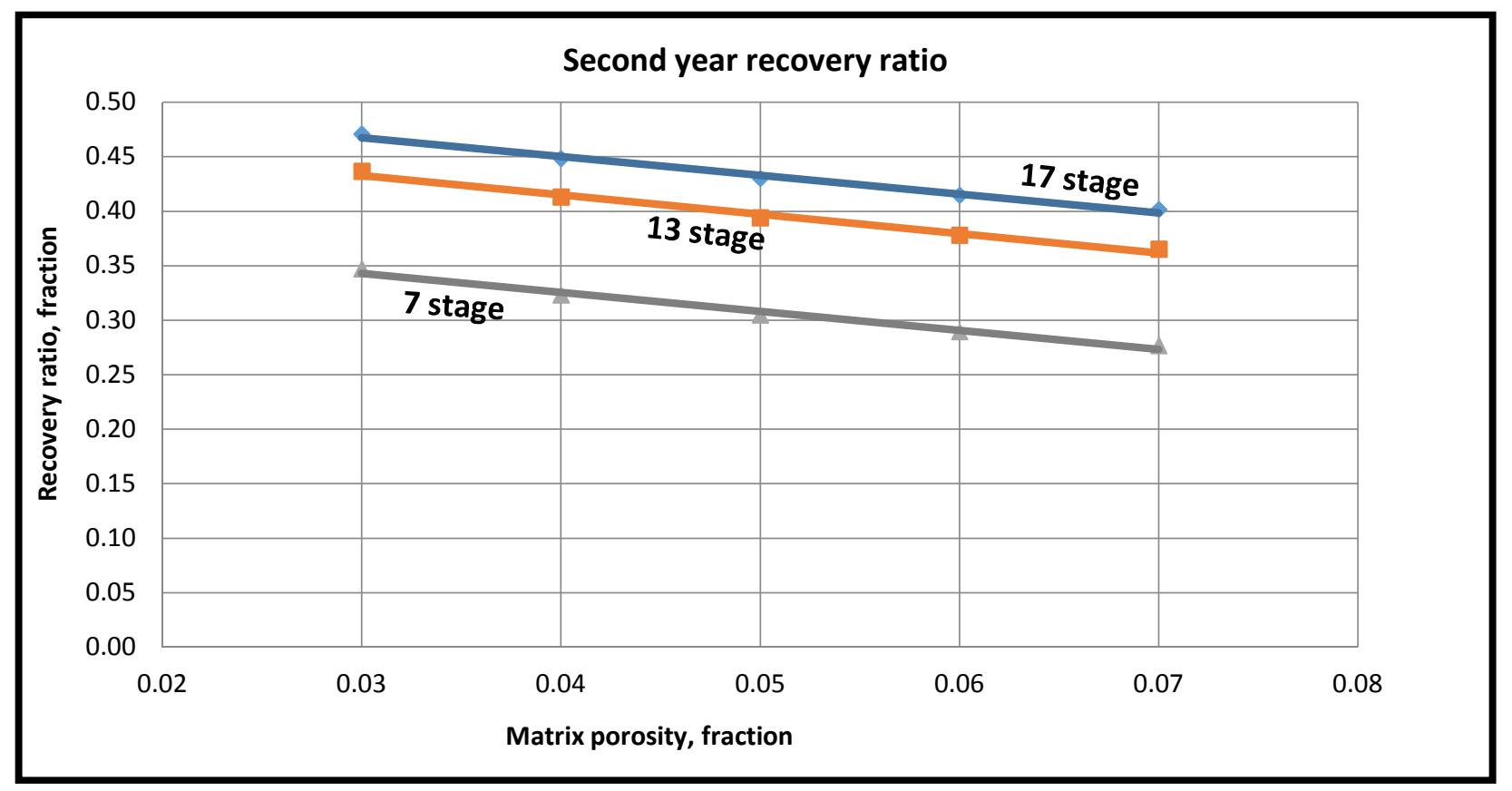

Figure 20: Impact the number of fractures on the recovery ratio based on $2^{\text {nd }}$ year production

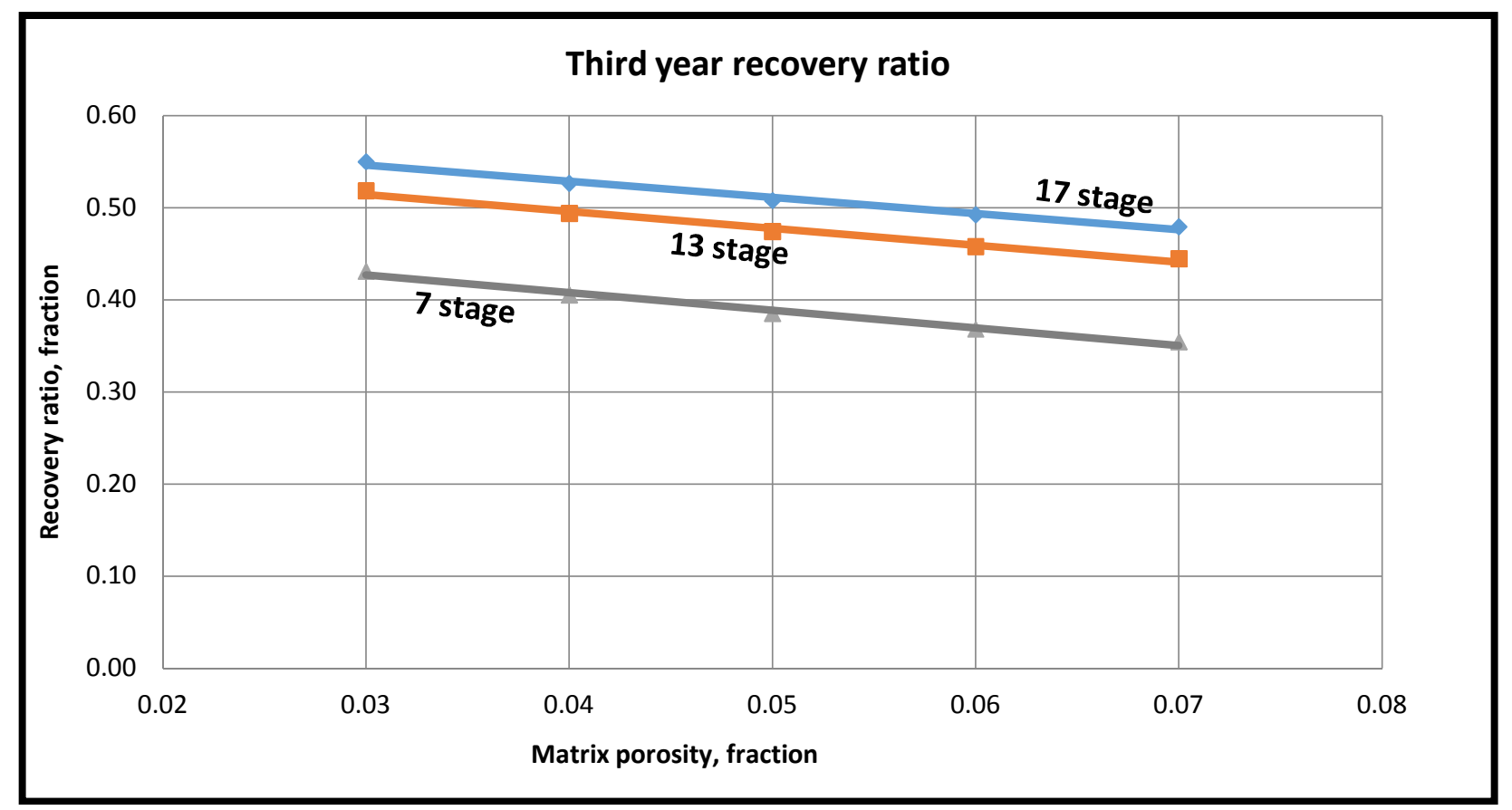

Figure 21: Impact the number of fractures on the recovery ratio based on $3^{\text {rd }}$ year production 


\section{The impact of fracture half length $\left(x_{f}\right)$}

Different values of fracture half length were investigated in this study 350, 500 and 650 ft. for 7 stage hydraulic fracture, the variation of the fracture half length $\left(\mathrm{X}_{\mathrm{f}}\right)$ does not affect the recovery ratio in the first year when the $\emptyset_{m}$ is 0.07 . However, the values of $\left(\mathrm{X}_{\mathrm{f}}\right)$ found out to have more impact as the value of matrix porosity is decreased. Figure 22 shows the impact of $\left(\mathrm{X}_{\mathrm{f}}\right)$ on the recovery ratio with 7 stages.

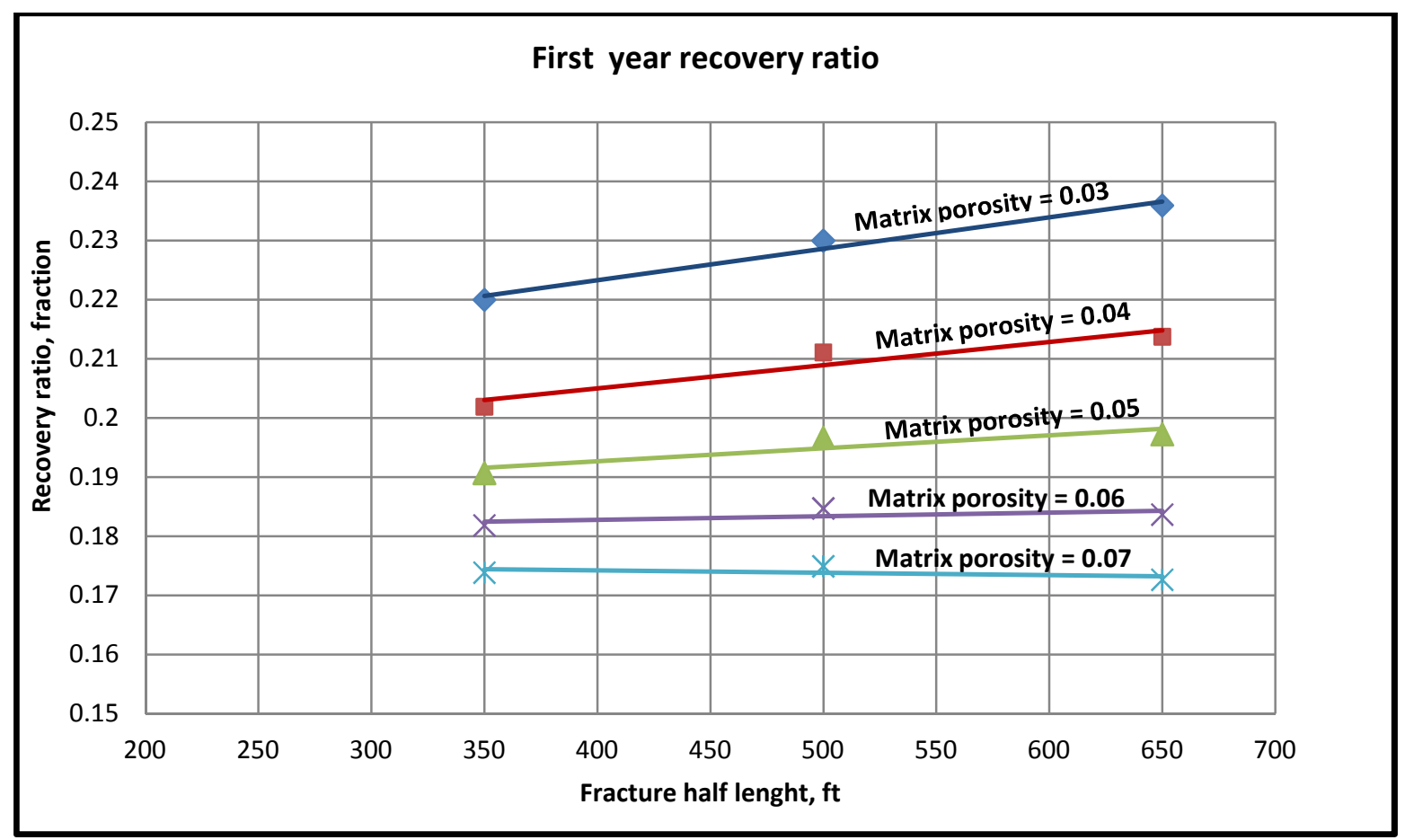

Figure 22: Impact Xf values on recovery ratio with different of $\emptyset_{m}$ for 7-stage hydraulic fracture

As can be shown in Figure 23 and 24, the impact of fracture half length on the recovery ratio increases as number of hydraulic fracture increases to 13 and 17 stages respectively. The rest of correlations for second and third year recovery ratio are in Appendix Figure 31 to 36. 


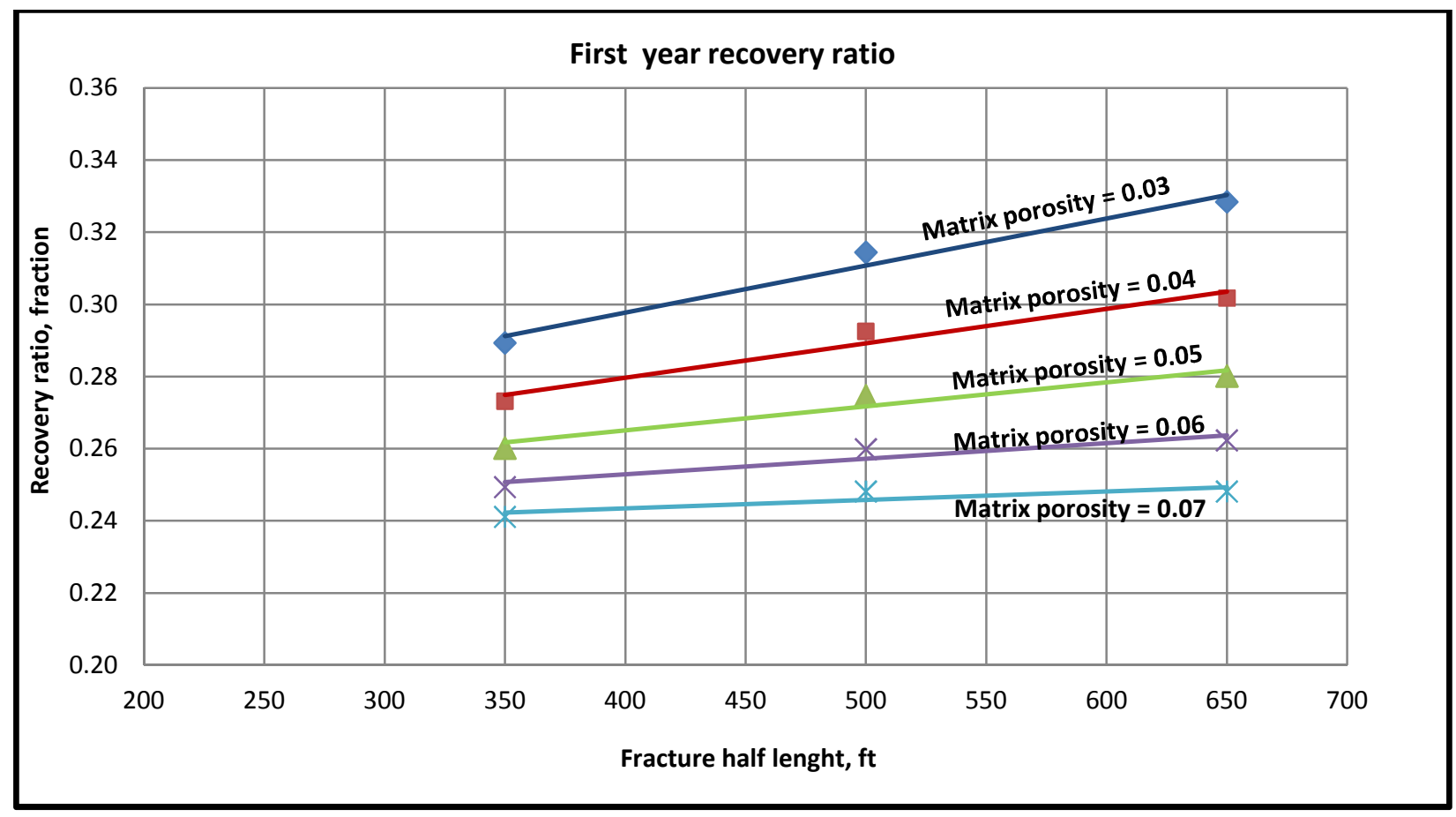

Figure 23: Impact Xf values on recovery ratio with different of $\emptyset \mathrm{m}$ for 13-stage hydraulic fracture

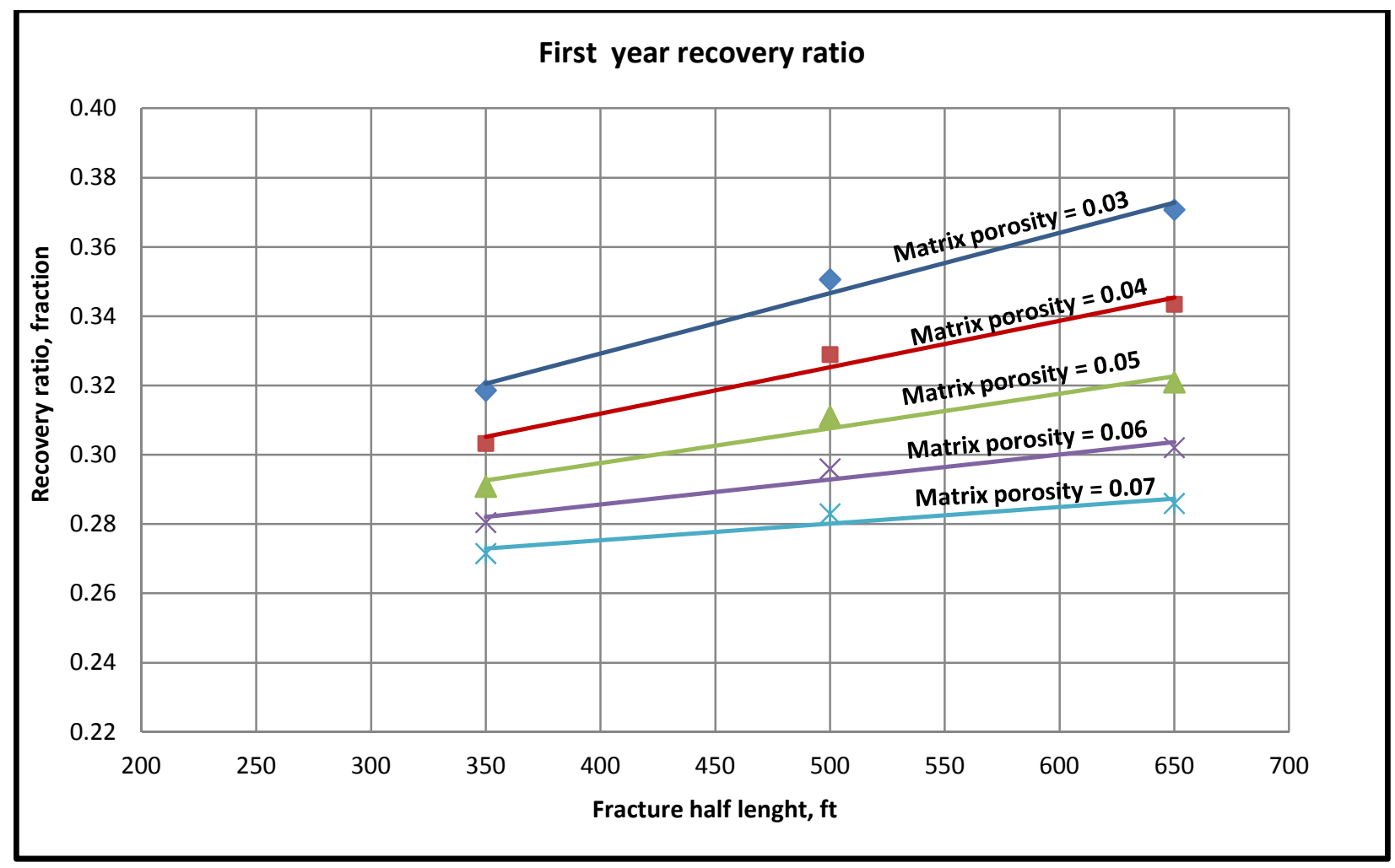

Figure 24: Impact Xf values on recovery ratio with different of $\emptyset \mathrm{m}$ for 17-stage hydraulic fracture 


\section{Case study for Verification}

To evaluate the reliability of the correlation, verification was performed. A set of parameters in Table 6 were used to predict thirty years production. These parameters were used as inputs into the correlations below Figure $25 \& 26$ and the simulator to compare the result. Table 7 illustrates the output from the correlations and the simulator for both cases using first year recovery ratio.

Table 6: Input data for case study

\begin{tabular}{|l|c|l|}
\hline \multicolumn{3}{|c|}{ Case1 } \\
\hline Matrix porosity & 0.045 & fraction \\
\hline Fracture half length & 400 & $\mathrm{ft}$. \\
\hline Number of stages & 13 & fracture \\
\hline \multicolumn{3}{|c|}{ Case2 } \\
\hline Matrix porosity & 0.045 & fraction \\
\hline Fracture half length & 500 & ft. \\
\hline Number of stages & 10 & fracture \\
\hline
\end{tabular}

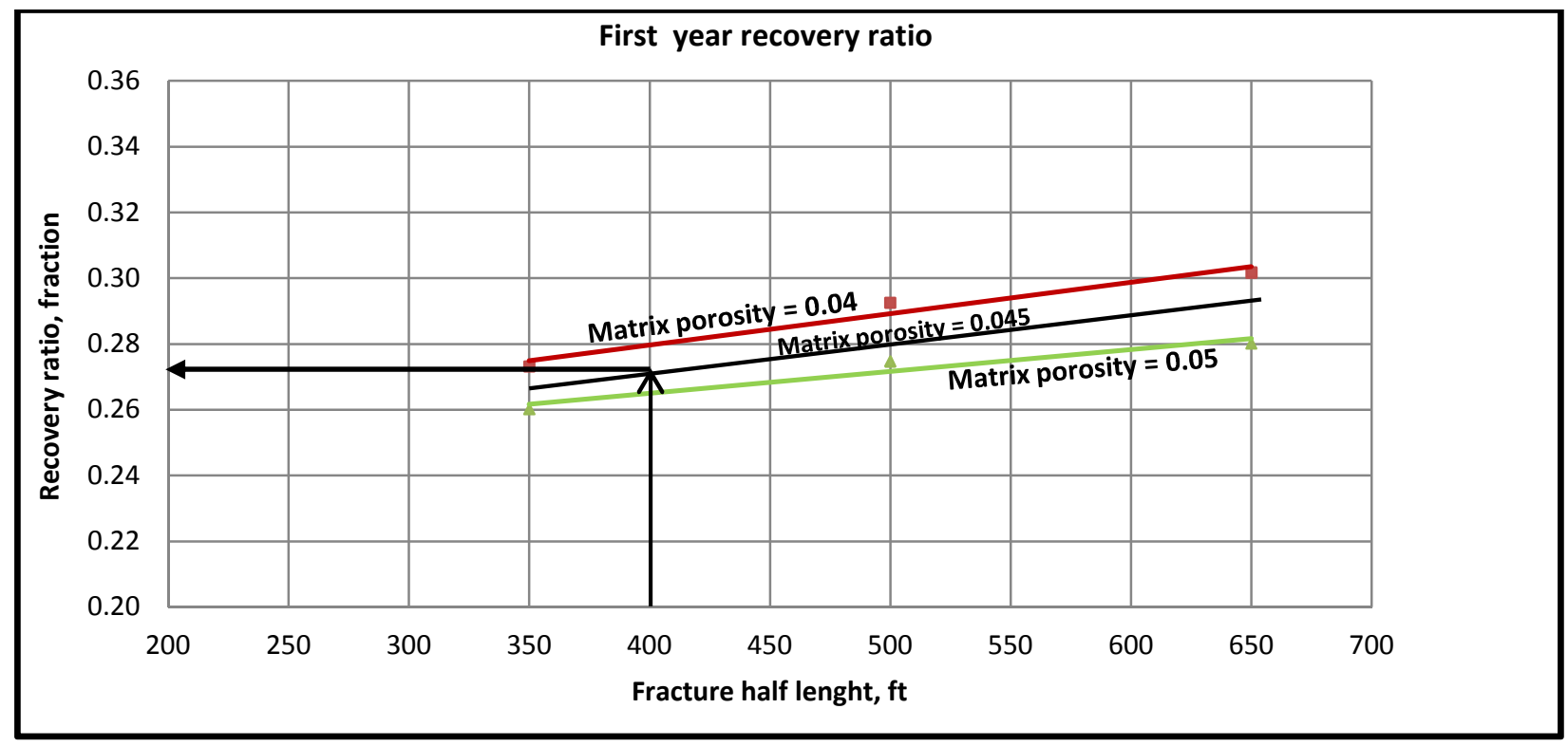

Figure 25: Correlation Q1/Q30 for 13-stage hydraulic fracture (case1) 


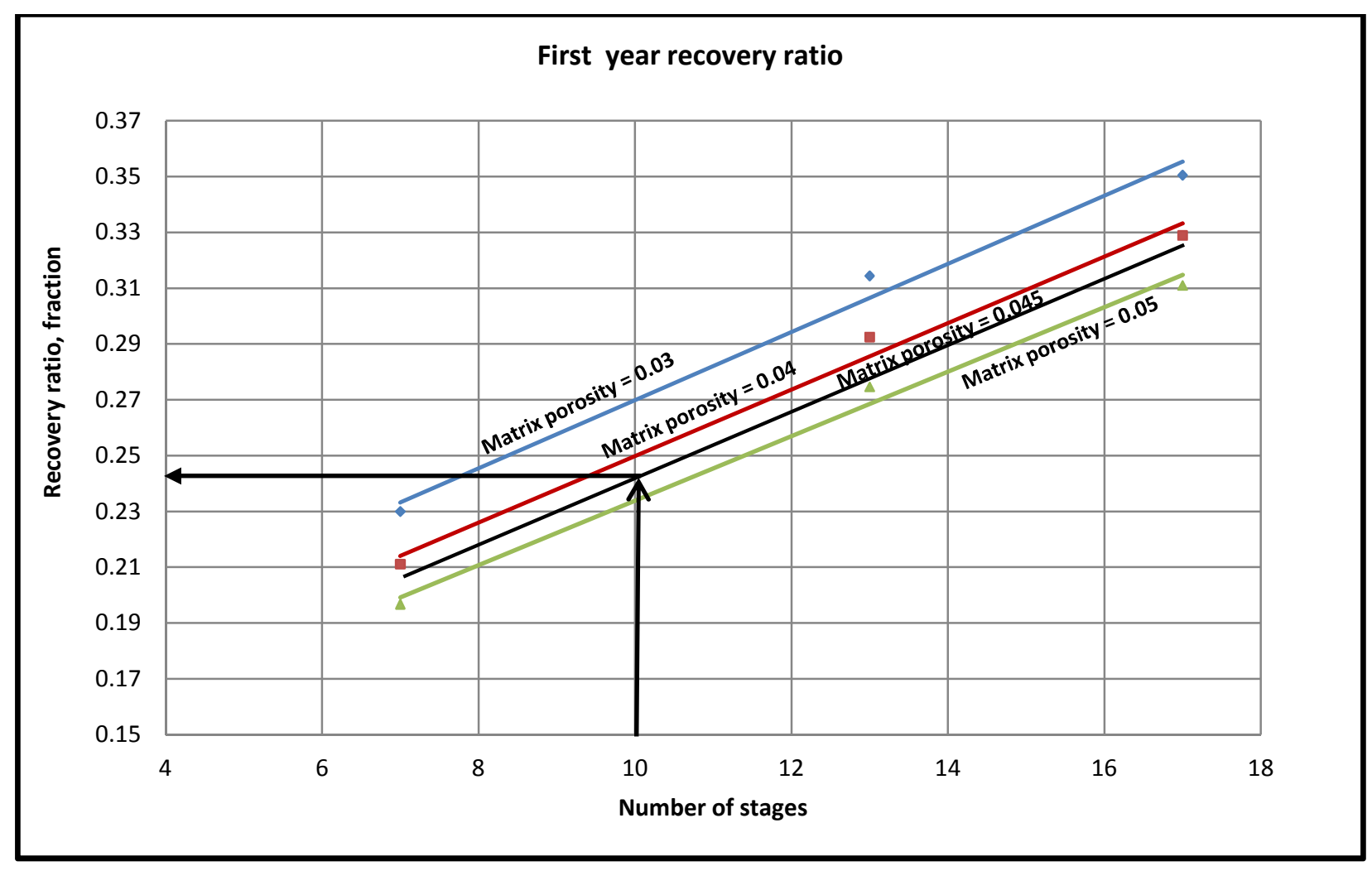

Figure 26: Correlation Q1/Q30 for fracture half length $500 \mathrm{ft}$. (case2)

Table 7: Compare the result from the correlations and the simulator using first year recovery ratio

\begin{tabular}{|c|c|c|c|c|}
\hline Case\# & $\begin{array}{c}\text { Q1 } \\
\text { MMcf }\end{array}$ & $\begin{array}{c}\text { Recovery ratio } \\
\text { from the } \\
\text { correlation, } \\
\text { fraction }\end{array}$ & $\begin{array}{c}\text { Predicted thirty } \\
\text { year production } \\
\text { from the } \\
\text { correlation, } \\
\text { MMcf }\end{array}$ & $\begin{array}{c}\text { Predicted thirty } \\
\text { year production } \\
\text { from the simulator, } \\
\text { MMcf }\end{array}$ \\
\hline $\mathbf{1}$ & 1,220 & 0.273 & $\underline{\mathbf{4 , 4 6 9}}$ & $\underline{\mathbf{4 , 5 0 1}}$ \\
\hline $\mathbf{2}$ & 1,117 & 0.244 & $\underline{\mathbf{4 , 5 8 0}}$ & $\underline{\mathbf{4 , 6 1 7}}$ \\
\hline
\end{tabular}

The result for using the second and third year recovery ratio to predict the thirty year production are shown in Table $8 \& 9$ respectively. Figures 27 to 30 are employed to get the ratio recovery for second and third year. 
Table 8: Compare the result from the correlations and the simulator using second year recovery ratio

\begin{tabular}{|c|c|c|c|c|}
\hline Case\# & $\begin{array}{c}\text { Q2 } \\
\text { MMcf }\end{array}$ & $\begin{array}{c}\text { Recovery ratio } \\
\text { from the } \\
\text { correlations, } \\
\text { fraction }\end{array}$ & $\begin{array}{c}\text { Predicted thirty } \\
\text { year production } \\
\text { from the } \\
\text { correlation , } \\
\text { MMcf }\end{array}$ & $\begin{array}{c}\text { Predicted thirty year } \\
\text { production from the } \\
\text { simulator, } \\
\text { MMcf }\end{array}$ \\
\hline $\mathbf{1}$ & 1,715 & 0.382 & $\underline{\mathbf{4 , 4 9 2}}$ & $\underline{\mathbf{4 , 5 0 1}}$ \\
\hline $\mathbf{2}$ & 1,643 & 0.357 & $\underline{\mathbf{4 , 6 0 2}}$ & $\underline{\mathbf{4 , 6 1 7}}$ \\
\hline
\end{tabular}

Table 9: Compare the result from the correlations and the simulator using Third year recovery ratio

\begin{tabular}{|c|c|c|c|c|}
\hline Case\# & $\begin{array}{c}\text { Q3 } \\
\text { MMcf }\end{array}$ & $\begin{array}{c}\text { Recovery ratio } \\
\text { from the } \\
\text { correlations, } \\
\text { fraction }\end{array}$ & $\begin{array}{c}\text { Predicted thirty } \\
\text { year production } \\
\text { from the } \\
\text { correlation, } \\
\text { MMcf }\end{array}$ & $\begin{array}{c}\text { Predicted thirty year } \\
\text { production from the } \\
\text { simulator, } \\
\text { MMcf }\end{array}$ \\
\hline $\mathbf{1}$ & 2,051 & 0.456 & $\underline{\mathbf{4 , 4 9 8}}$ & $\underline{\mathbf{4 , 5 0 1}}$ \\
\hline $\mathbf{2}$ & 2,011 & 0.435 & $\underline{\mathbf{4 , 6 2 5}}$ & $\underline{\mathbf{4 , 6 1 7}}$ \\
\hline
\end{tabular}

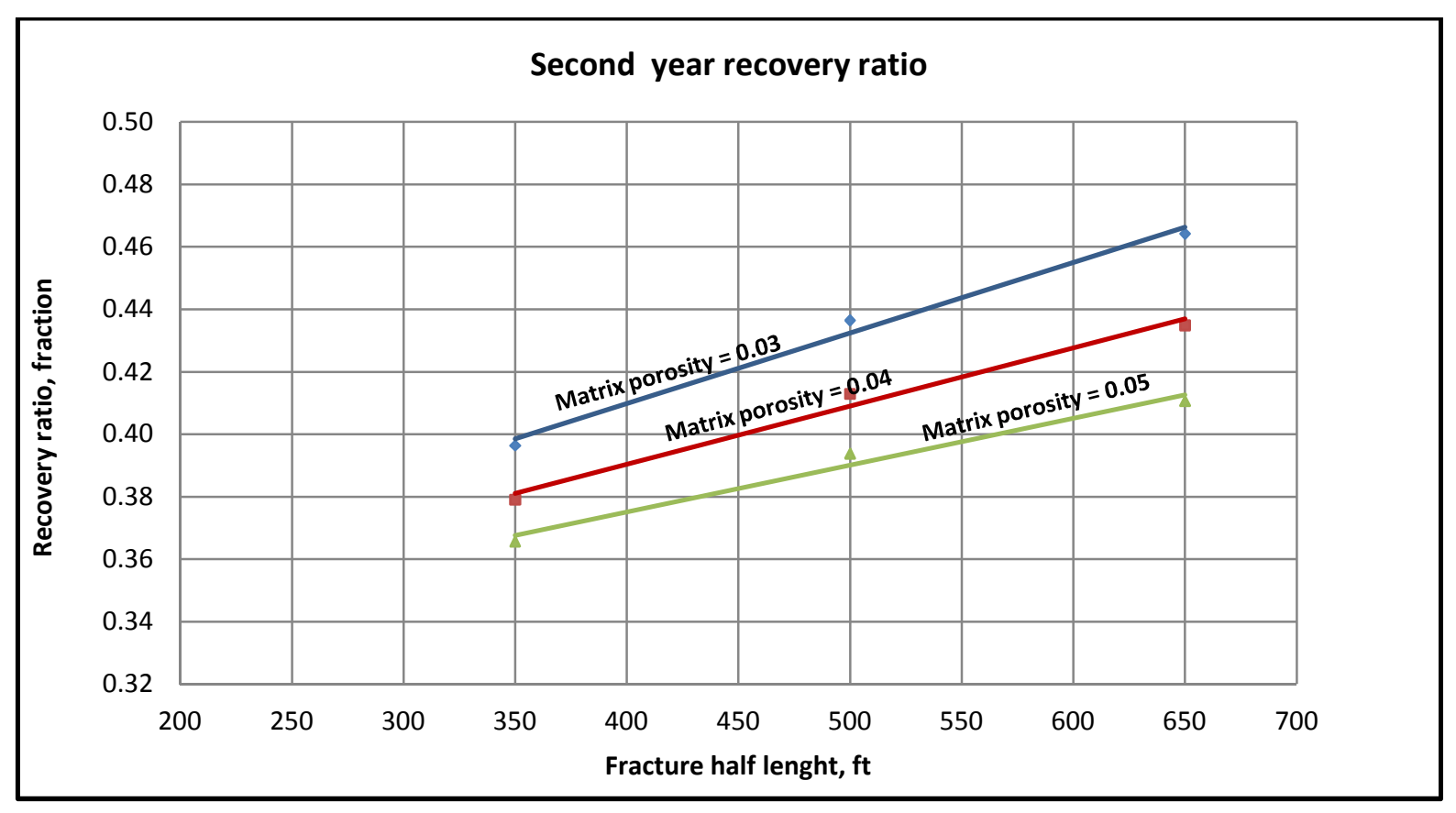

Figure 27: Correlation Q2/Q30 for 13-stage hydraulic fracture (case1) 


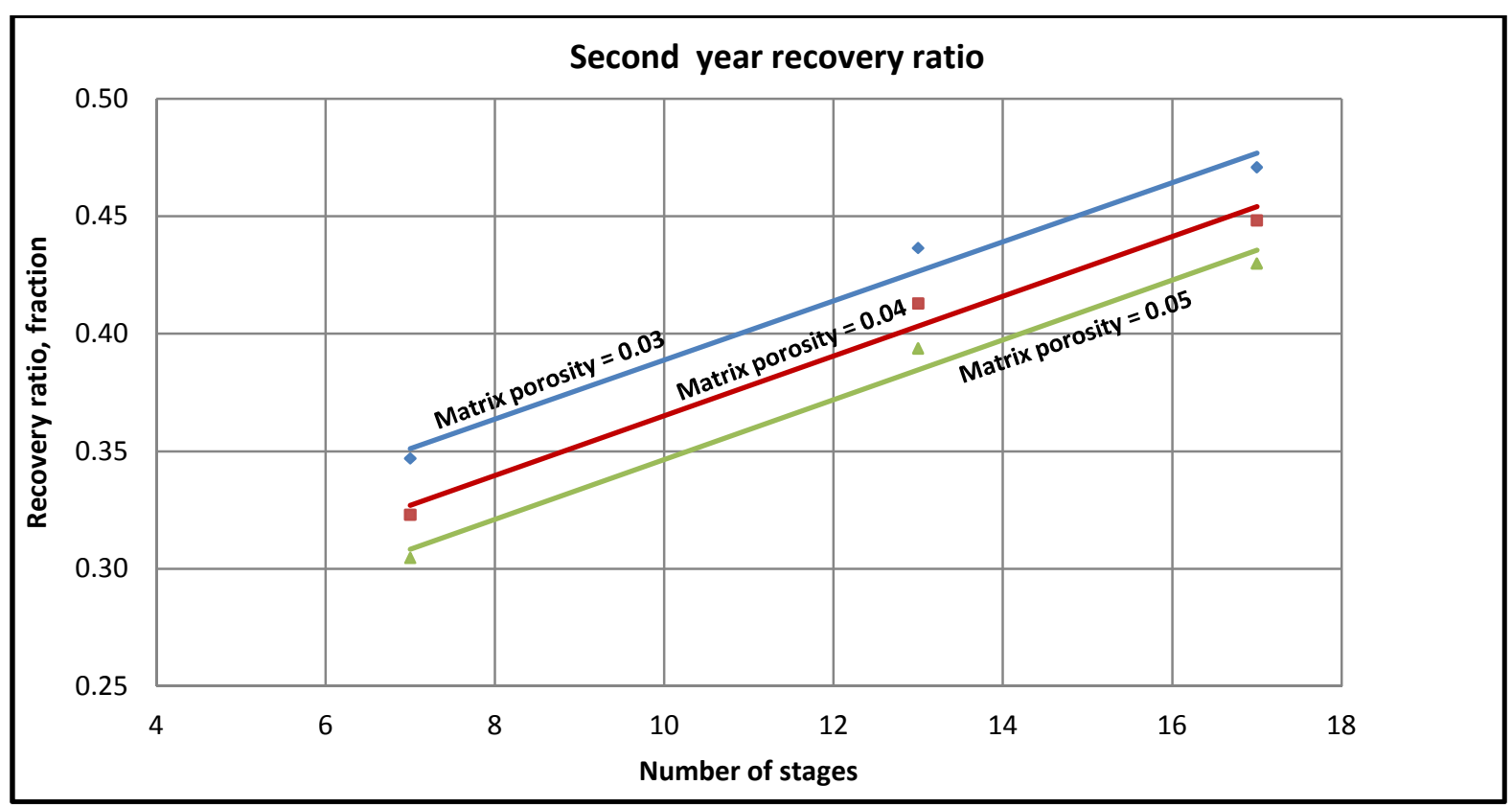

Figure 28: Correlation Q2/Q30 for fracture half length $500 \mathrm{ft}$. (case2)

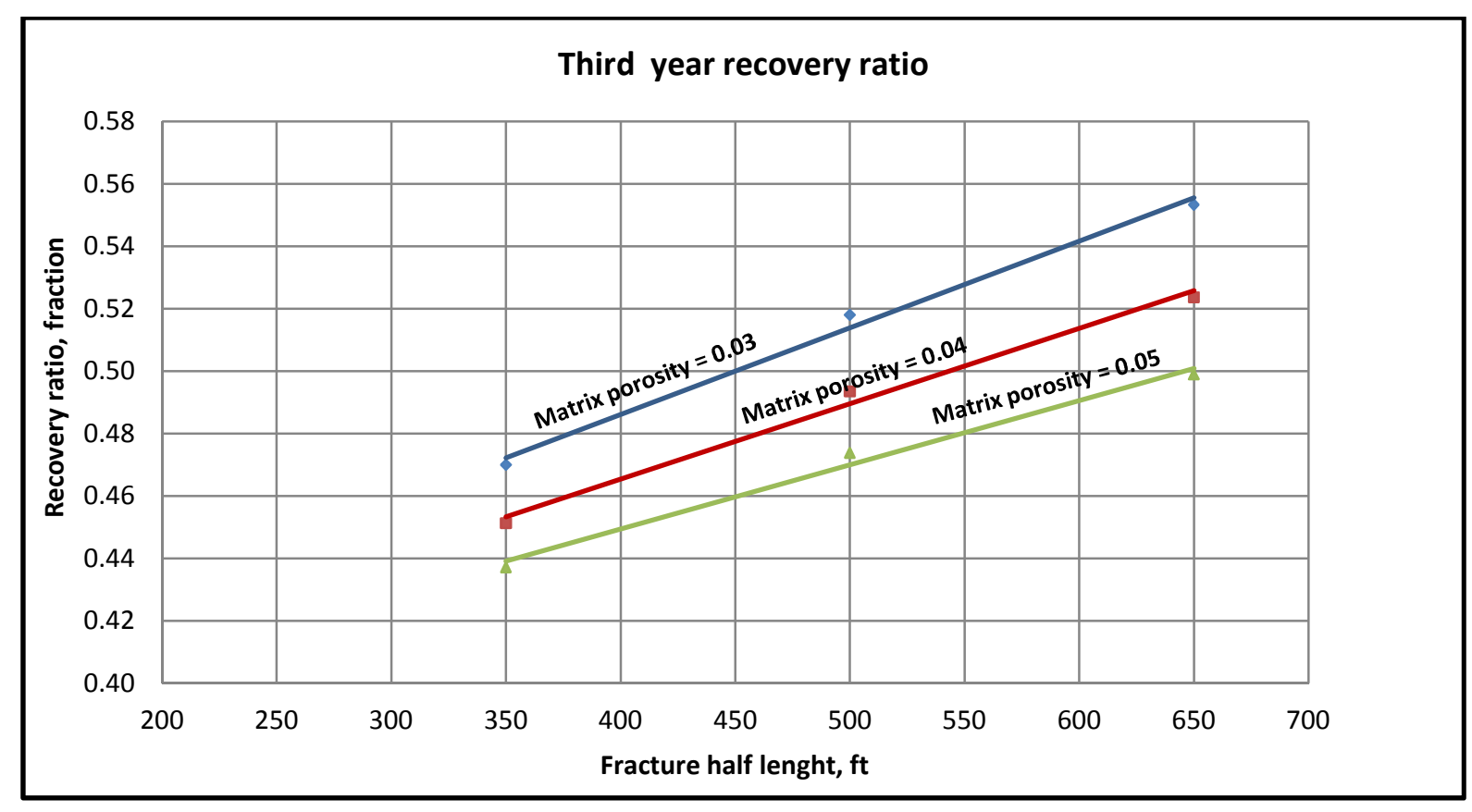

Figure 29: Correlation Q3/Q30 for 13-stage hydraulic fracture (case1) 


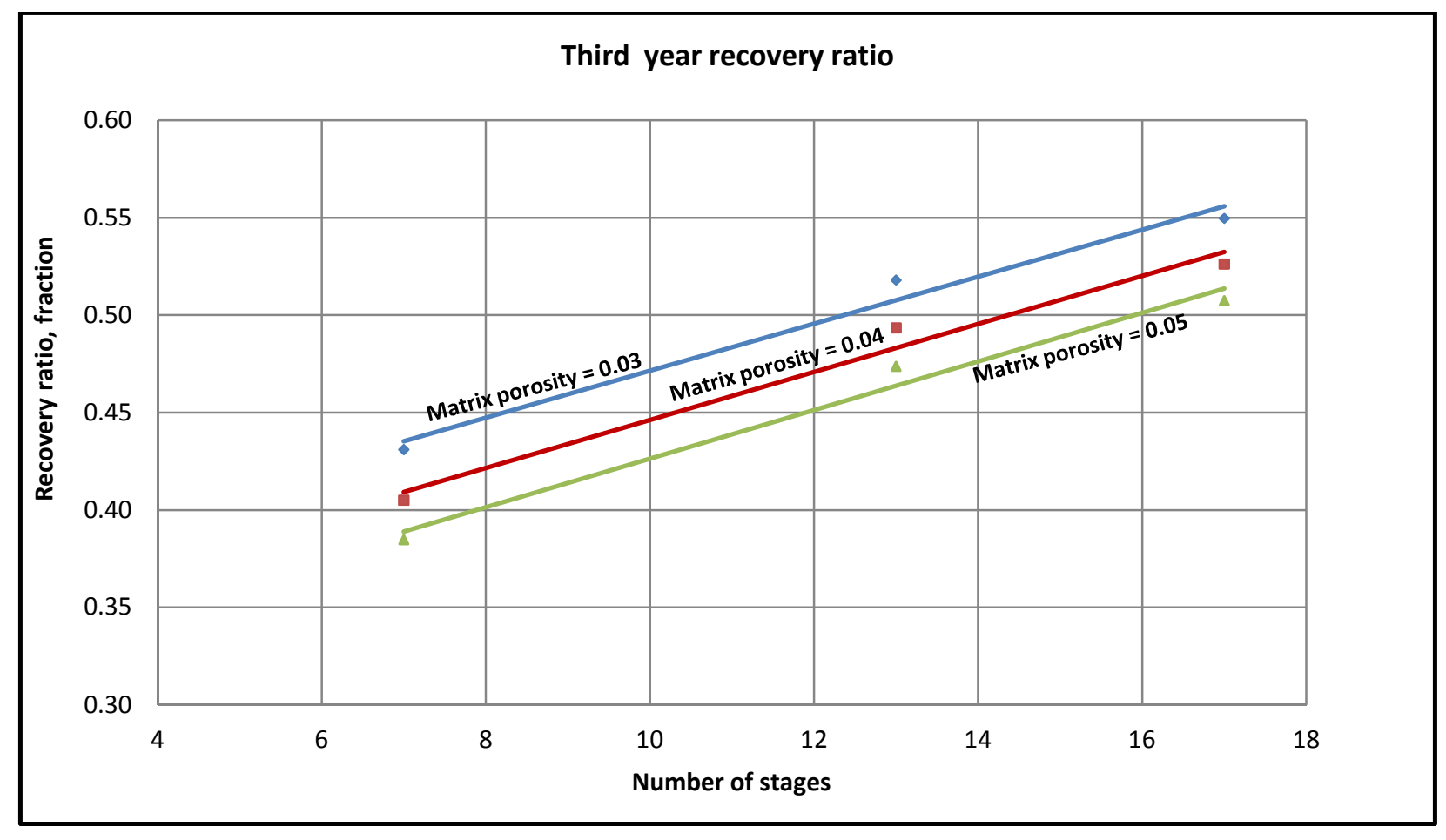

Figure 30: Correlation Q3/Q30 for fracture half length $500 \mathrm{ft}$. (case2) 


\section{CHAPTER 5 \\ CONCLUSIONS AND RECOMMENDATIONS}

The main purpose of this study is to develop correlations for estimating the gas recovery from horizontal well with multiple hydraulic fractures completed in a shale formation based on the early production history. In addition the impacts of the reservoir and fracture properties on the correlations were investigated. The approach to perform a model for horizontal well with a number of hydraulic fractures was by using Schlumberger's Eclipse software tool. The major conclusions of this work can be summarized as follows:

1. The numbers of hydraulic fractures and the matrix porosity have significant impacts on the recovery ratio.

2. The fracture half-length impact on the ratio is significant only when the matrix porosity is low.

3. Natural fracture permeability has a minor impact on the recovery ratio.

4. The comparison of the predicted 30-year production by recovery ratio correlation and the simulation model indicates that reliable estimates of gas recovery can be obtained by using the recovery ratio correlation.

The results presented in this study are based on the assumed values of drainage area and horizontal well length. Therefore, it is recommended to extend this research to evaluate the impacts of these model parameters on the correlations. Additionally, it will also useful to develop correlations for the recovery ratio based on 10-year cumulative production due to the economic significance of gas production during this period. 


\section{REFERENCES}

1. Belyadi, A., Aminian K., and Ameri, S.: "Production Performance of the Multiply Fractured Horizontal Wells.” SPE 153894, SPE Western Regional Conference, Bakersfield, California, USA, 2012.

2. Chunlou Li, Randy Lafollette, Andy Sookprasong, Sharon Wang, Baker Hughes: "Characterization of Hydraulic Fracture Geometry in Shale Gas Reservoirs Using Early Production Data” SPE 16896, International Petroleum Technology Conference, Beijing, China, 26-28 March, 2013.

3. EIA. 2008. Annual Energy Outlook 2008 with Projections to 2030, http:// www.eia.doe.gov /oiaf/aeo/pdf /0383 (2008).pdf, Access May, 2014.

4. How Much Gas Is There In The Marcellus Shale, http://forbes.com/sites/christopherhelman /2011/10/11/how-much-gas-is-there-in-the-marcellus-shale, Download May, 2014.

5. How Much Natural Gas Can The Marcellus Shale Produce, http://extensuon.psu.edu/ Naturalresources/natural-gas/news/2012/05/how-much-natural-gas-can-marcellusshale-produce, Access, May 2014.

6. Joseph H. Frantz, Schlumberger Data \& Consulting Services; Walter K. Sawyer, Schlumberger Data \& Consulting Services; Ronald James MacDonald, Schlumberger Data \& Consulting Services et al. "Evaluating Barnett Shale Production PerformanceUsing an Integrated Approach,” SPE 96917 SPE Annual Technical Conference and Exhibition, Dallas, Texas, USA, 9-12 October 2005. 
7. Larch, K., Aminian K., and Ameri S.: "The Impact of Multistage Fracturing on the Production Performance of the Horizontal Wells in Shale Formations." SPE 161347, SPE Eastern Regional Meeting, Lexington, Kentucky, USA, 3-5 October 2012.

8. Nelson B., Belyadi F., Mashayekhi A., Aminian K., and Ameri S.: "Predicting Longterm Production Behavior of the Marcellus Shale.” SPE 169489, SPE Western North American and Rocky Mountain Joint Regional Meeting, Denver, California, USA, 16-18 April 2014.

9. Marcellus Shale - Appalachian Basin Natural Gas Play, http://geology.com/articles/ marcellus-shale.shtml, Download March 26, 2014.

10. Shale Gas, http://www.cgg.com/default.aspx?cid=3503\&lang=1, Access April, 2014. 11. What is Shale Gas, http://geology.com/energy/shale-gas, Access March, 2014. 


\section{Appendix}

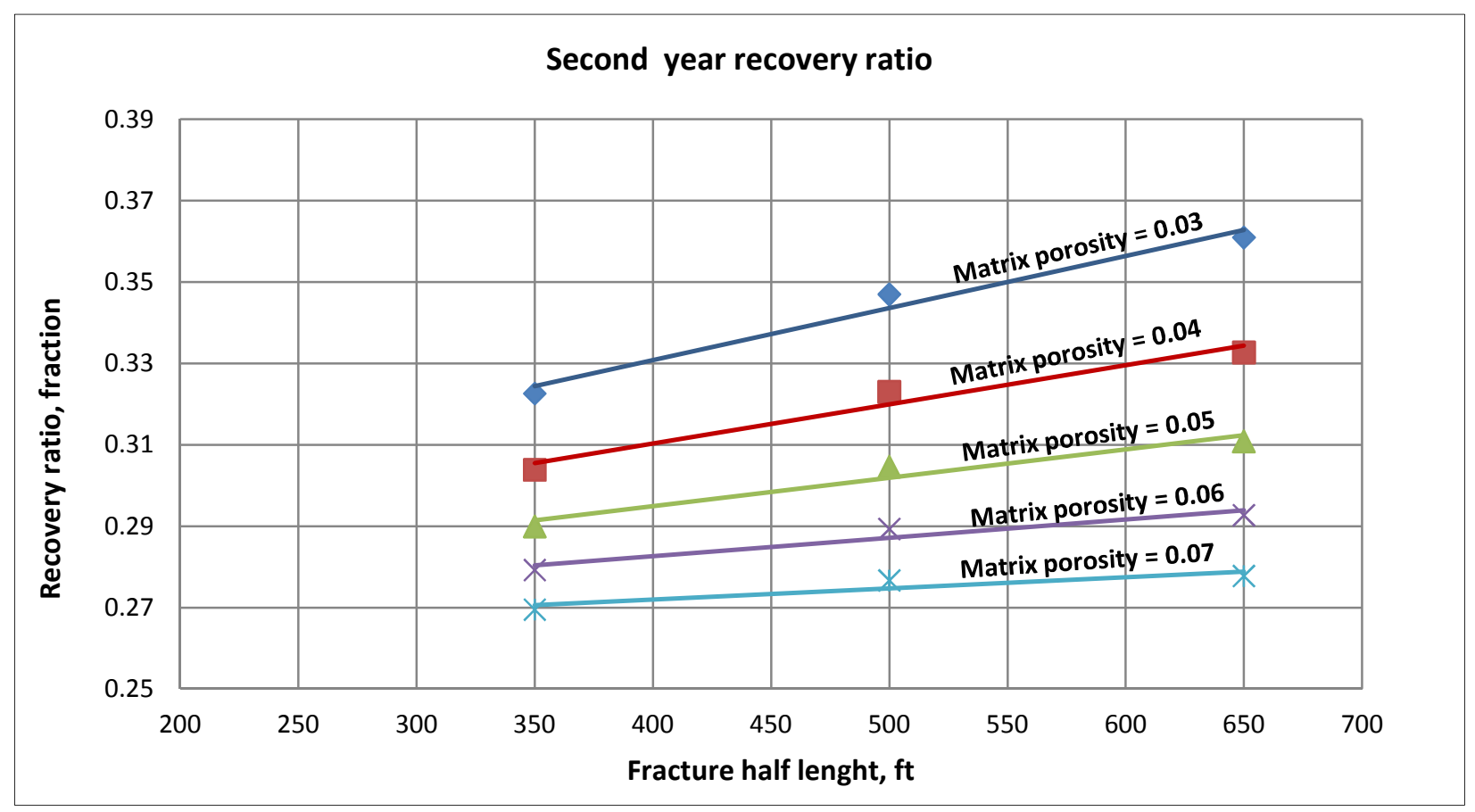

Figure 31: Impact Xf values on recovery ratio with different of $\emptyset \mathrm{m}$ for 7-stage hydraulic fracture

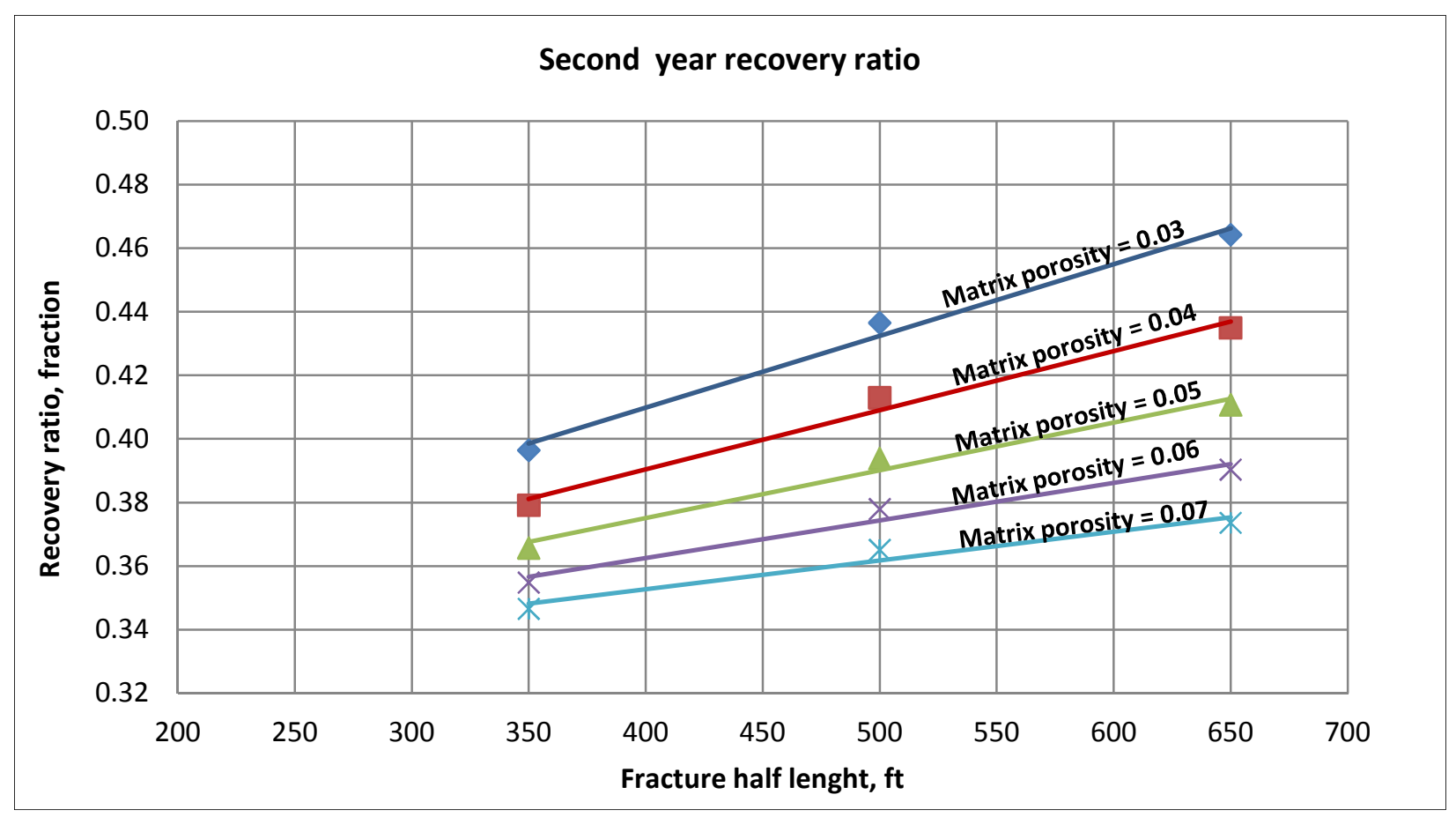

Figure 32: Impact Xf values on recovery ratio with different of $\emptyset \mathrm{m}$ for 13 -stage hydraulic fracture 


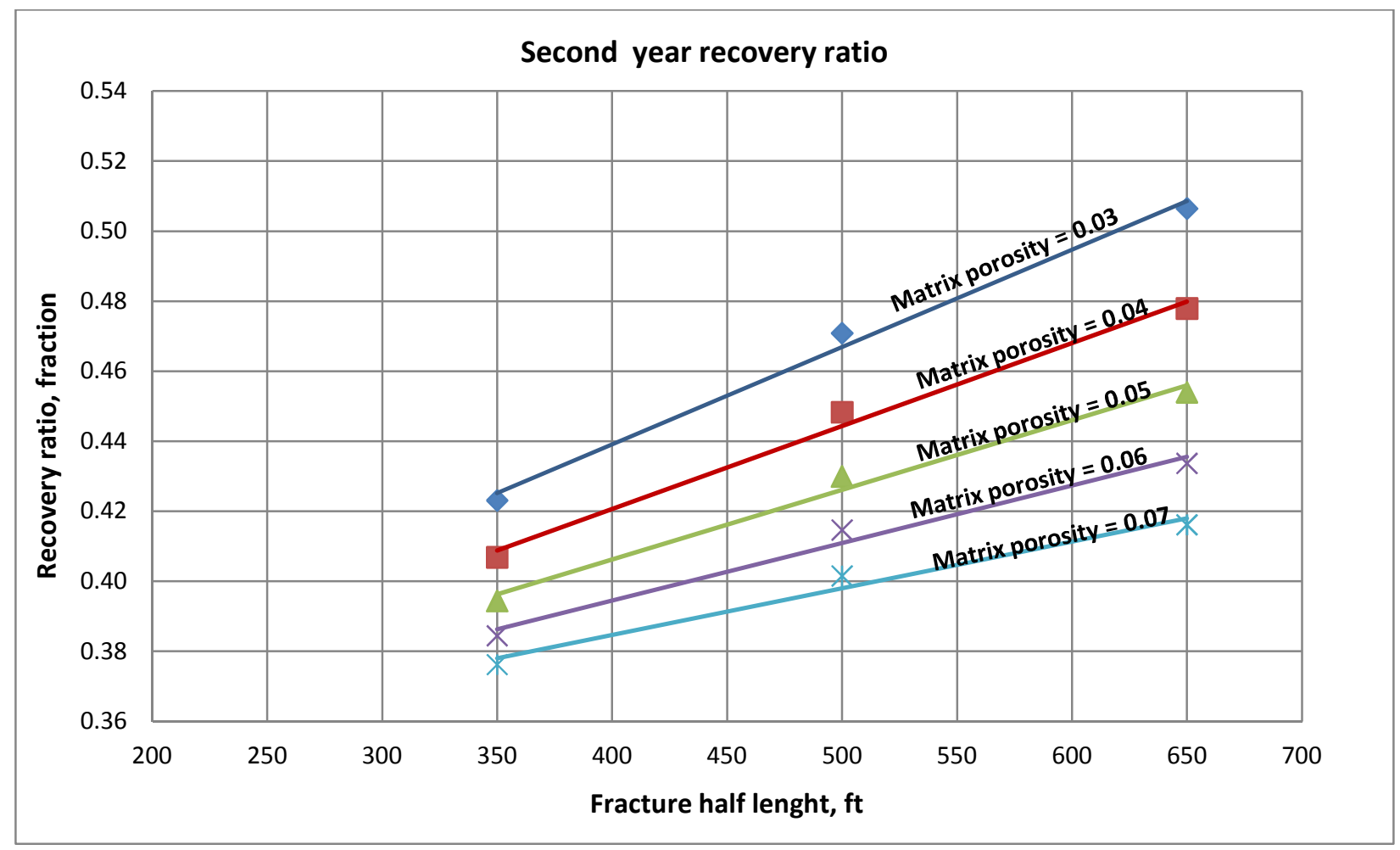

Figure 33: Impact Xf values on recovery ratio with different of $\emptyset \mathrm{m}$ for 17 -stage hydraulic fracture

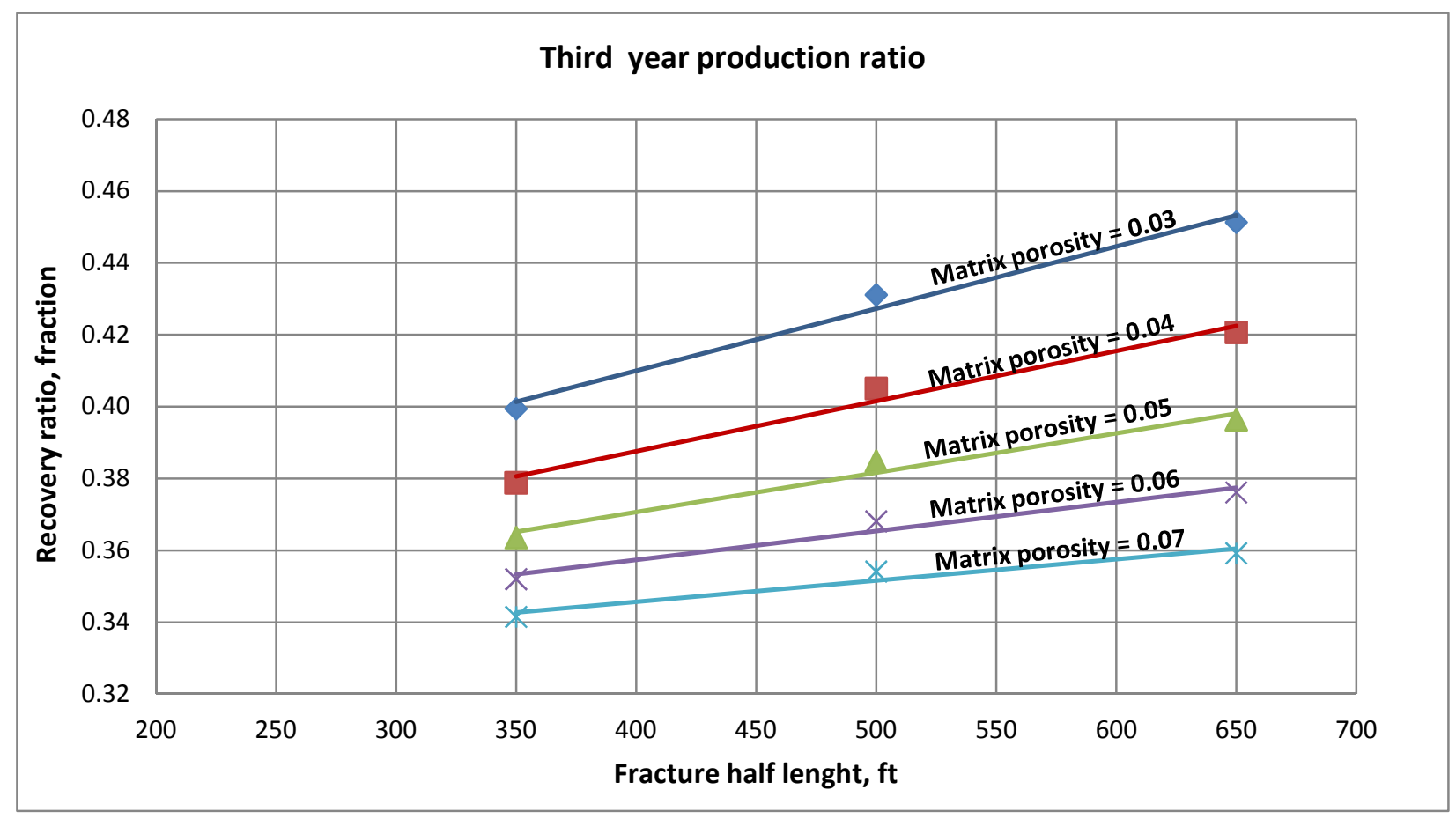

Figure 34: Impact Xf values on recovery ratio with different of $\emptyset \mathrm{m}$ for 7-stage hydraulic fracture 


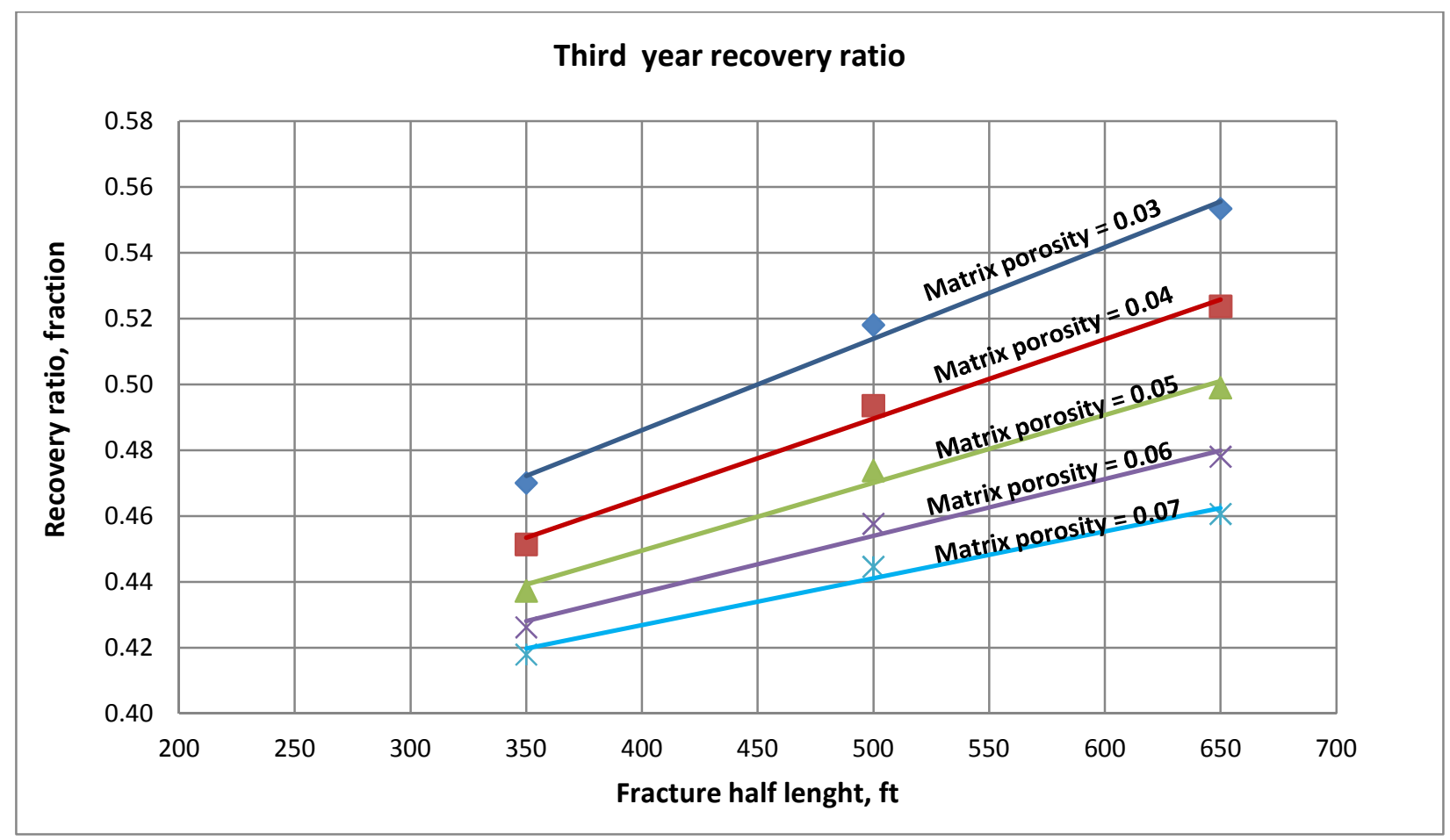

Figure 35: Impact Xf values on recovery ratio with different of $\emptyset \mathrm{m}$ for 13-stage hydraulic fracture

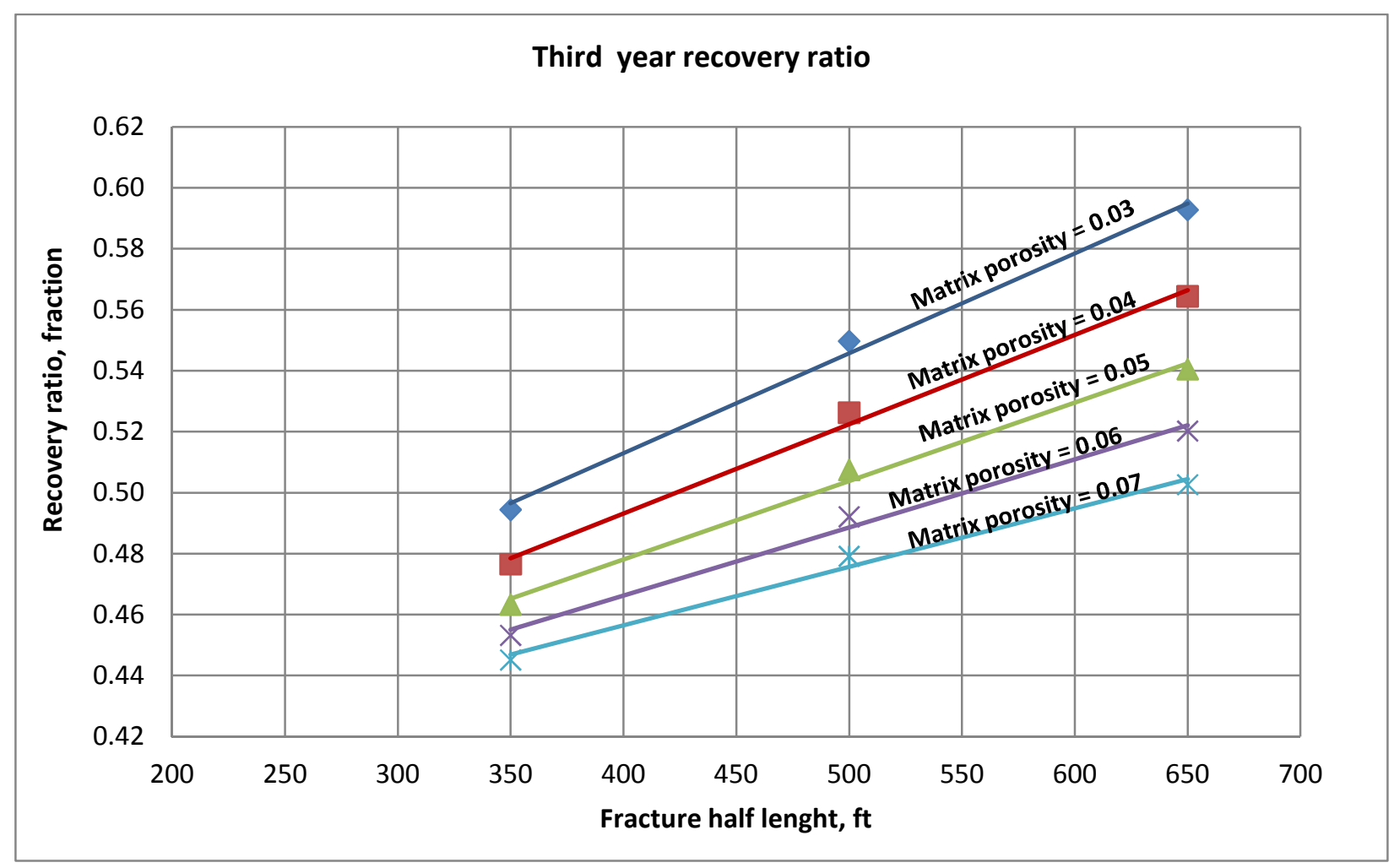

Figure 36: Impact Xf values on recovery ratio with different of $\emptyset \mathrm{m}$ for 17 -stage hydraulic fracture 


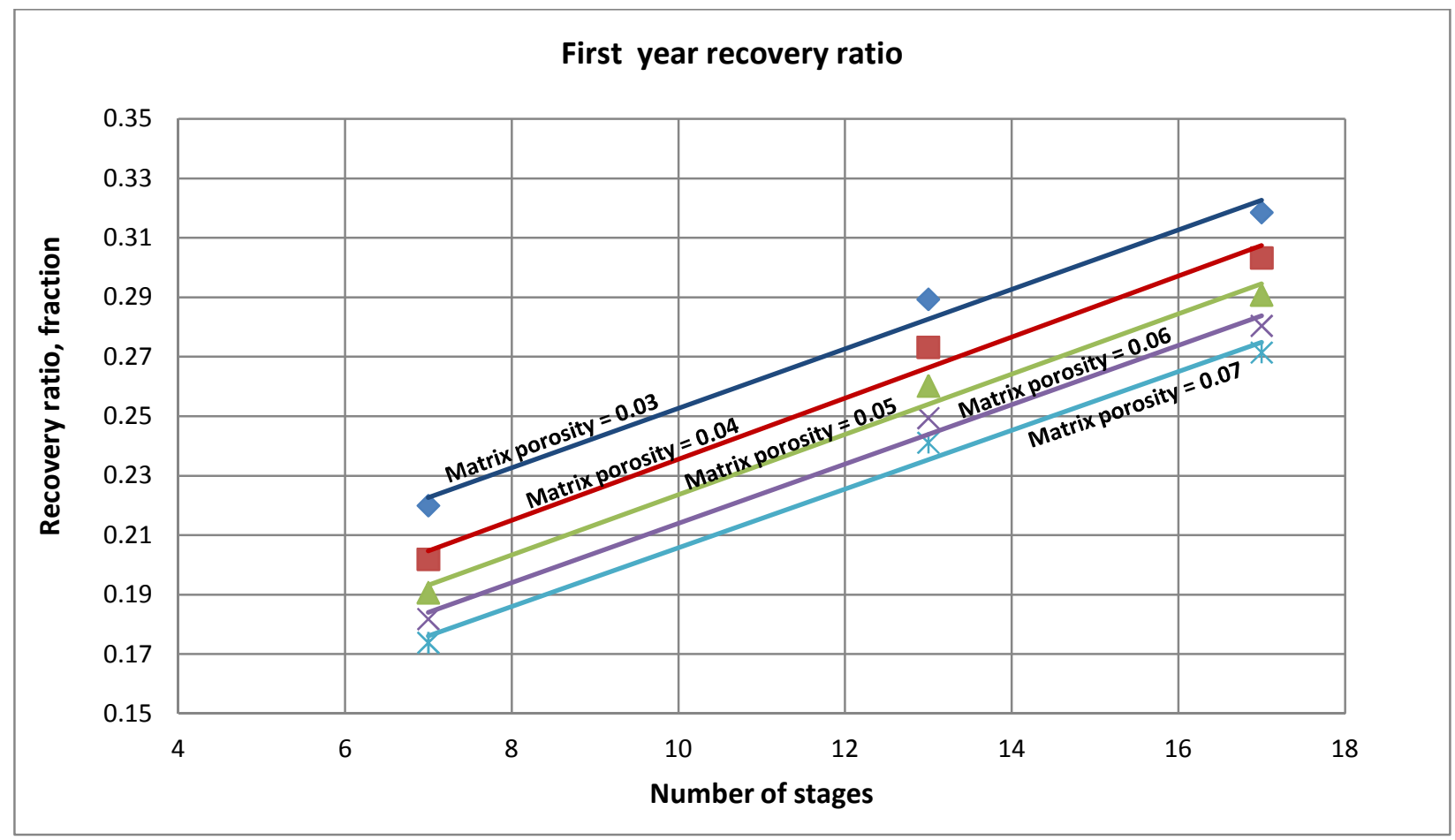

Figure 37: Correlation Q1/Q30 when Xf = $350 \mathrm{ft}$.

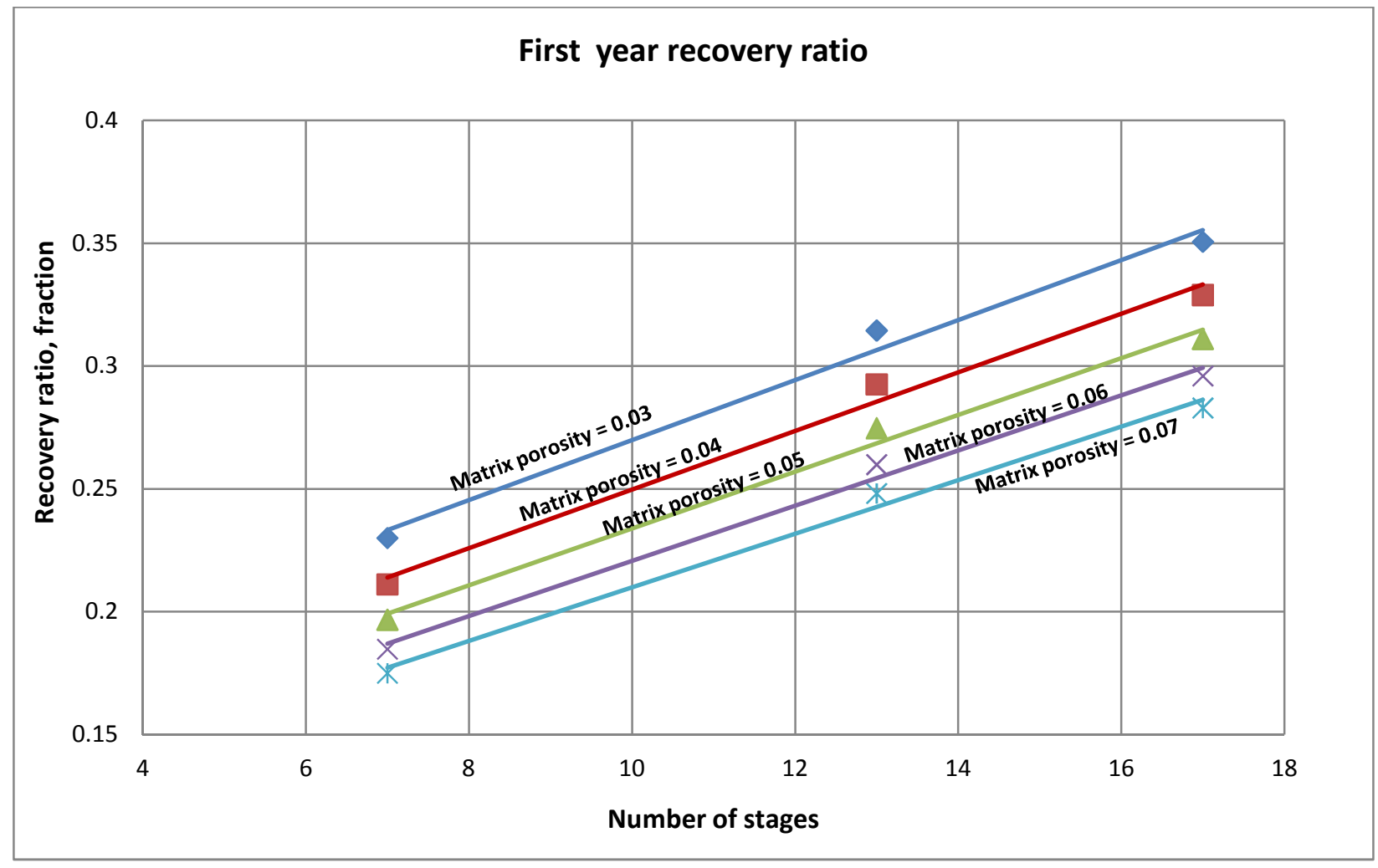

Figure 38: Correlation Q1/Q30 when Xf = $500 \mathrm{ft}$. 


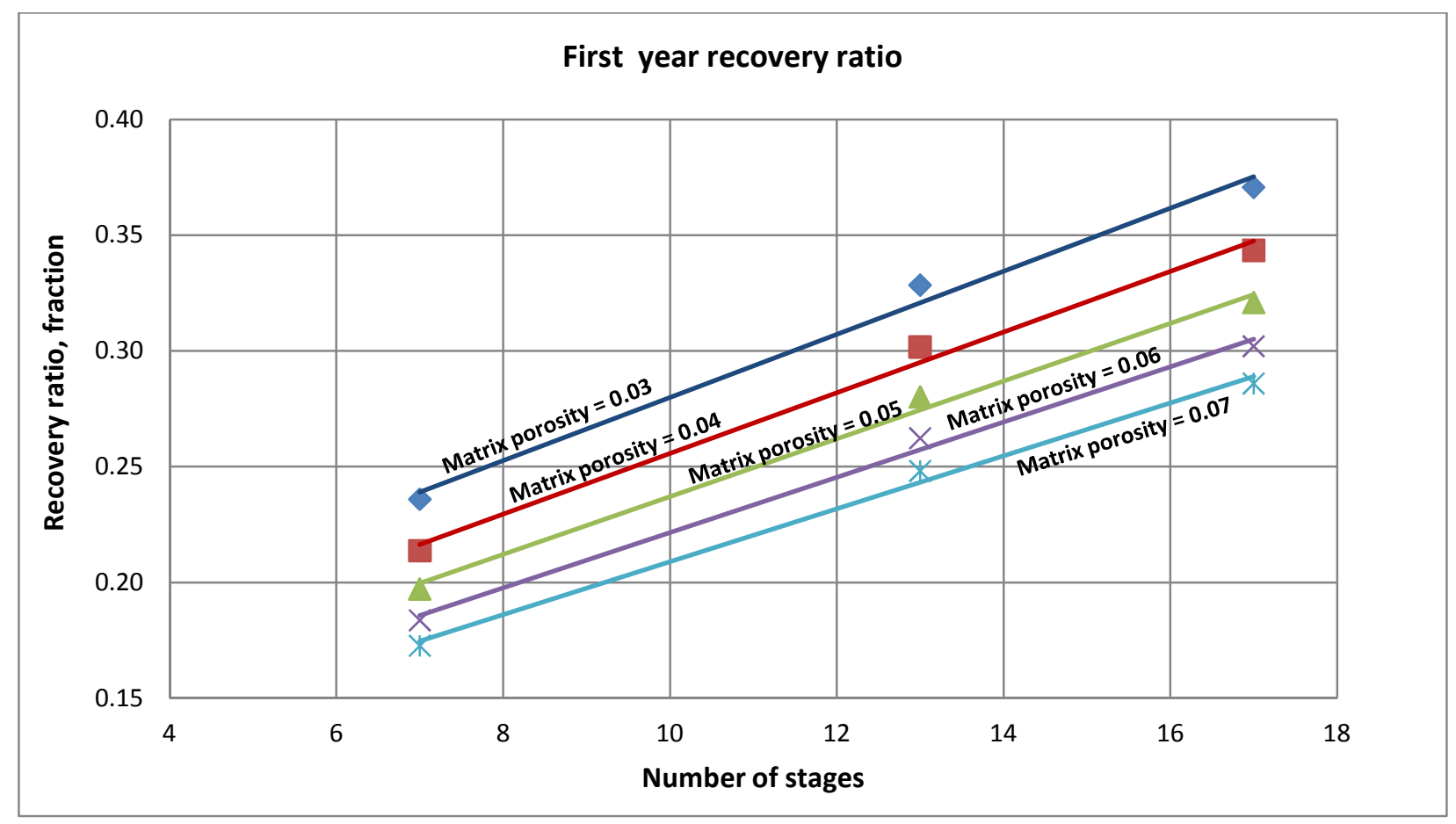

Figure 39: Correlation Q1/Q30 when Xf $=650 \mathrm{ft}$. 